\title{
Risk Factors for Poor Outcomes Among Patients with Extensively Drug-Resistant Tuberculosis (XDR-TB): A Scoping Review
}

\section{Karan Varshney \\ Beverly Anaele \\ Matthew Molaei \\ Rosemary Frasso \\ Vittorio Maio}

College of Population Health, Thomas Jefferson University, Philadelphia,

PA, USA
Correspondence: Karan Varshney College of Population Health, Thomas Jefferson University, 90 I Walnut Street, 10th Floor, Philadelphia, PA, 19107, USA

Tel + | 604-359-672 |

Email karan.varshney@students.jefferson. edu

\begin{abstract}
In recent years, there has been an upsurge in cases of drug-resistant TB, and strains of TB resistant to all forms of treatment have begun to emerge; the highest level of resistance is classified as extensively drug-resistant tuberculosis (XDR-TB). There is an urgent need to prevent poor outcomes (death/default/failed treatment) of XDR-TB, and knowing the risk factors can inform such efforts. The objective of this scoping review was to therefore identify risk factors for poor outcomes among XDR-TB patients. We searched three scientific databases, PubMed, Scopus, and ProQuest, and identified 25 articles that examined relevant risk factors. Across the included studies, the proportion of patients with poor outcomes ranged from 8.6 to $88.7 \%$. We found that the most commonly reported risk factor for patients with XDR-TB developing poor outcomes was having a history of TB. Other risk factors were human immunodeficiency virus (HIV), a history of incarceration, low body mass, being a smoker, alcohol use, unemployment, being male, and being middle-aged. Knowledge and understanding of the risk factors associated with poor outcomes of XDR-TB can help policy makers and organizations in the process of designing and implementing effective programs.
\end{abstract}

Keywords: drug-resistant, tuberculosis, risk factors, compliance, adherence, XDR-TB

\section{Introduction}

An estimated 1.7 billion people are currently infected with Mycobacterium tuberculosis, ${ }^{1}$ the causative agent of tuberculosis (TB). TB was the leading cause of mortality from a single pathogen in 2018, with the bacterium being the attributed caused of approximately 1.5 million deaths worldwide. ${ }^{2}$

Successful treatment of TB is crucial to both curing the individual patient and reducing the transmission of Mycobacterium tuberculosis in the community. Firstline treatment includes combination of chemotherapy, such as isoniazid, rifampicin, pyrazinamide, and ethambutol. ${ }^{3}$ However, A major issue is the widespread prevalence of drug-resistant TB (DR-TB). At least 5\% of all global cases of TB have some form of drug-resistance, that is, resistance to at least one first-line anti-TB drug. ${ }^{4}$ Multi-drug resistant TB (MDR-TB) is defined as resistance to at least two first-line anti-TB drugs, isoniazid and rifampin, ${ }^{2}$ and extensively drug-resistant TB (XDR-TB) is defined as resistance to isoniazid and rifampin, as well as any fluoroquinolone and any Group A TB drug (the most potent second-line drugs, and include levofloxacin, bedaquiline, linezolid, and moxifloxacin). ${ }^{5}$ Pre- 
extensively drug-resistant TB (pre-XDR-TB) is defined as resistance to isoniazid and rifampin, as well as any fluoroquinolones. ${ }^{5}$

Drug-susceptible TB (DS-TB) is tuberculosis that is susceptible to all forms of standard treatment, and is normally treated with isoniazid, rifampin, pyrazinamide, and ethambutol. ${ }^{6,7}$ Compared to patients with DS-TB, patients with drug-resistant strains of TB have considerably longer treatment regimens (regimens can be as long as 18-24 months for resistant strains compared to the standard 6-month regimen for non-resistant strains in DS-TB patients) which are more costly (treatment for XDR-TB can cost more than 25 times that of standard treatment [ $\$ 494,000 \mathrm{USD}$ compared to $\$ 17,000 \mathrm{USD}]^{8}$ ), and the negative side-effects of the drugs are more severe. Due to the difficulties associated with treatment, patients with DR-TB have higher default rates for treatment compared to those with DS-TB. ${ }^{9,10}$

Concerns about drug-resistant infections have been on the rise in recent years, with $\mathrm{TB}$ cases resistant to all available forms of treatment among the most worrisome. The first reported cases were described in Italy and Germany in 2007. ${ }^{11}$ Additional reports of cases came from Iran in 2009, followed by India in 2012, and South Africa in $2013 .{ }^{12-14}$ Since the emergence of these initial cases, it is not clearly understood how many more cases, which are resistant to all forms of treatment, have emerged.

Cases that have been identified as XDR-TB comprise an estimated $5.4 \%$ of all cases of DR-TB, or approximately $0.3 \%$ (5.1 million) of all global cases of TB. ${ }^{15}$ However, cases of XDR-TB may be greatly underestimated because some patients may receive care in the private sector and because many individuals living in under-resourced settings never receive a diagnosis or treatment. ${ }^{16,17}$

The outlook for new antimicrobial drugs against XDRTB is grim. Despite the urgent need, only minimal, new classes of antibiotics have been created in recent years. Antibiotics, such as those needed to treat TB, have a very low economic return, and so pharmaceutical companies devote only limited amounts of resources to their development. ${ }^{18}$ Moreover, there are sizeable additional costs, along with other difficulties, associated with distributing drugs to regions experiencing XDR-TB. Lastly, once XDR-TB becomes prevalent in an area, it holds the potential to spread - as is the case with any drug-resistant disease or infection-with catastrophic consequences. ${ }^{19-21}$
XDR-TB incidence has been rising in recent years. ${ }^{22}$ Furthermore, it has been demonstrated that XDR-TB patients have poorer outcomes (death/treatment default/ failure) at rates much higher than those of non-XDR-TB patients. ${ }^{23}$ Considering the extent of this issue, controlling XDR-TB is a very important global health priority. To better address this global health issue, more information is needed about the risk factors for poor outcomes associated with this infection. A review on the risk factors for XDR-TB that analyzed the literature published from 2006 to 2010 found that risk factors for developing XDR-TB included immigration status, HIV coinfection, alcoholism, having previously been infected with $\mathrm{TB}$, and having preXDR-TB $;{ }^{15}$ however, the authors noted that the literature was quite limited and that a more thorough investigation of possible risk factors is needed. ${ }^{15}$ While a recent systematic review has focused on the risk factors for poor outcomes among DR-TB, minimal detail was given regarding risk factors specifically for XDR-TB. ${ }^{24}$ Therefore, the purpose of this scoping review was to provide information on risk factors associated with poor outcomes for patients with XDR-TB.

\section{Methods}

Two reviewers (KV and BA) independently searched PubMed, Scopus and ProQuest, with the workflow following the "Preferred Items for Systematic Review and MetaAnalyses extension for Scoping Reviews" (PRISMA-ScR) guidelines. ${ }^{25,26}$ All searches were conducted on July 10, 2020. As this review expands on a systematic review conducted in 2014 by Flor de Lima and Tavares, which analyzed risk factors for XDR-TB in studies published up to June $2010,{ }^{15}$ our searches were restricted to articles published after June 2010.

The most highly resistant forms of TB have been described in the literature in a number of different ways, aside from XDR-TB. These include: total drug-resistant $\mathrm{TB},{ }^{27,28}$ totally drug-resistant $\mathrm{TB},{ }^{11-14}$ (TDR-TB), super extensively drug-resistant TB (SXDR-TB or super XDRTB), ${ }^{12,29}$ extra extensively drug-resistant TB (XXDRTB), ${ }^{11,30}$ pan-resistant $\mathrm{TB},{ }^{36,37}$ pan drug-resistant $\mathrm{TB}$ (PDR-TB), ${ }^{30-33,38,39}$ untreatable $\mathrm{TB},{ }^{34,35,40}$ untreatable drug-resistant $\mathrm{TB},{ }^{36,37}$ incurable $\mathrm{TB},{ }^{20,41}$ and incurable drug-resistant $\mathrm{TB}^{42,43}$ The term extremely drug-resistant TB has also, in some cases, been given the same abbreviation as extra extensively drug-resistant TB (XXDR$\mathrm{TB}),{ }^{38,42}$ and, in others, the same as abbreviation as extensively drug-resistant $\mathrm{TB}(\mathrm{XDR}-\mathrm{TB})^{39,40}$ In order to 
account for this variation in terminology, all of these terms were included as search terms in our review. Additionally, our search terms referred to population-level factors and individual-level factors, as well as outcomes. Complete search terms are listed in Table 1.

Eligible settings included any region in the world where there have been recorded instances of XDR-TB. For the review process, the two reviewers screened potential articles for eligibility based on title, abstract, keywords, and date of publication. Duplicates were removed and all remaining full-text articles were then assessed. Data were extracted from each study if they satisfied the following inclusion criteria: (1) had a longitudinal design, (2) were originally published in English, (3) provided an analysis of population-level and/or individual-level risk factors, (4) provided stratified data for patients with poor outcomes (death/default/failed treatment) despite initial treatment, (6) described the prevalence of at least one of the levels of resistance described in Table 1, and (7) included at least 10 patients who ended up with poor outcomes. There was no registered study protocol for this review.

Data collection and extraction was conducted by utilizing the process from Flor de Lima and Tavares ${ }^{15}$ as a framework. From all included studies, we extracted data on study characteristics, such as: country, data source, study design, sampling method, proportion of XDR-TB cases compared to total cases of TB, and the proportion of patients with poor outcomes. Thereafter, we extracted data on patient characteristics related to the outcome of interest, including sex, age, comorbidities, history of TB, and additional relevant factors identified in the individual study. These additional factors included, but were not limited to smoking status, race, adverse events during treatment, and body mass index (BMI).

Study quality was assessed using the Joanna Briggs Institute's (JBI) critical appraisal tools. ${ }^{44}$ Study metrics that were assessed included reliability of exposure measurement, strategies to deal with confounding factors, validity of outcome measures, follow-up completion and loss of follow-up, and appropriateness of statistical of analyses. Following the approach taken in a number of different reviews, ${ }^{45-47}$ the JBI tools were modified to provide a total score based on the number of yes/no responses on an eleven-item scale for cohort studies, and ten-item scale for case-control studies, and were depicted graphically thereafter. Quality assessment scores are shown in Supplementary Tables 1 and 2.

Table I Search Terms by Category*

\begin{tabular}{|c|c|c|c|c|}
\hline Population & OR & Individual & AND & Outcomes \\
\hline $\begin{array}{l}\text { “Risk Factors”[Mesh] OR “Sociological } \\
\text { Factors”[Mesh] OR “Socioeconomic } \\
\text { Factors”[Mesh] OR “Social } \\
\text { Determinants of Health”[Mesh] OR } \\
\text { “Epidemiologic Factors”[Mesh] OR } \\
\text { “Biological Variation, Population”[Mesh] } \\
\text { OR “Genetics, Population”[Mesh] }\end{array}$ & & $\begin{array}{l}\text { “Biological Variation, Individual”[Mesh] } \\
\text { OR “Genetics, Behavioral”[Mesh] OR } \\
\text { “Health Risk Behaviors”[Mesh] OR } \\
\text { "Patient Compliance”[Mesh] OR } \\
\text { “Medication Adherence”[Mesh] OR “HIV } \\
\text { Infections”[Mesh] OR “Emigration and } \\
\text { Immigration”"[Mesh] OR “Poverty”[Mesh] } \\
\text { OR “Guideline Adherence”[Mesh] OR } \\
\text { "Disease Susceptibility”[Mesh] OR } \\
\text { "Coinfection”[Mesh] }\end{array}$ & & $\begin{array}{l}\text { “Extensively Drug-Resistant Tuberculosis” } \\
\text { OR “Extremely Drug-Resistant } \\
\text { Tuberculosis” OR “Extensively Drug- } \\
\text { Resistant Tuberculosis” OR “Extremely } \\
\text { Drug-Resistant Tuberculosis” OR “Extra } \\
\text { Extensively Drug-Resistant Tuberculosis” } \\
\text { OR “Super Extensively Drug-Resistant } \\
\text { Tuberculosis” “Totally Drug-Resistant } \\
\text { Tuberculosis” OR “Total Drug-Resistant } \\
\text { Tuberculosis” OR “Pan-Resistant } \\
\text { Tuberculosis” OR “Pan Drug-Resistant } \\
\text { Tuberculosis” OR “Pan Drug Resistant } \\
\text { Tuberculosis” OR “Untreatable } \\
\text { Tuberculosis” OR “Untreatable Drug- } \\
\text { Resistant Tuberculosis” OR “Incurable } \\
\text { Tuberculosis” OR “Incurable Drug- } \\
\text { Resistant Tuberculosis” OR “XDRTB” OR } \\
\text { "TDRTB” OR “XDR TB” OR “XXDR TB” } \\
\text { OR “TDR TB” OR “XDR-TB” OR } \\
\text { “XXDR-TB” OR “SXDR TB” OR } \\
\text { “PDRTB” OR “PDR TB” OR “SXDR-TB” } \\
\text { “SXDR TB” OR “SXDRTB” }\end{array}$ \\
\hline
\end{tabular}

Notes: *Mesh term used for PubMed, and its equivalent used for Scopus and ProQuest. 


\section{Results}

The initial searches produced 2825 articles. After removal of duplicates, 2150 remained, 1922 of which were excluded after screening by title and abstract. Of the 228 articles that remained, 25 articles $^{48-72}$ met eligibility requirements and were included in the final review. The complete workflow is listed in Figure 1.

The study characteristics for the 25 articles that were reviewed are described in Table 2 . The 25 articles provided data from 11 countries. One article provided data from four countries, ${ }^{48}$ whereas the other 24 articles each provided data from a single country only. Twelve articles focused on South Africa, ${ }^{53,55,56,60,62-67,70,71}$ four focused on China, ${ }^{50,61,69,72}$ four on Latvia, ${ }^{48,59}$ four on Estonia, ${ }^{48,52}$ four on Russia, ${ }^{49,68}$ and one on each of the following countries: India, ${ }^{57}$ Pakistan, ${ }^{58}$ Brazil,${ }^{51}$ Lithuania, ${ }^{48}$ Romania, ${ }^{48}$ and Georgia. ${ }^{5454}$

Of the articles included, 16 were retrospective cohort analyses, ${ }^{49-52,54-61,64-67}$ eight were prospective cohort analyses, ${ }^{46-50,62,63,68-70}$ and one was a case-control study. ${ }^{55}$ Twelve studies focused only on XDR-TB patients, ${ }^{49,50,54,60,62-}$ ${ }^{67,70,71}$ whereas the other 13 also included MDR-TB patients.48,51-53,61,68,69,72 Total number of patients ranged from 67-3270. The proportion of patients with poor outcomes ranged from $8.6 \%-88.7 \%$ across the studies.

Quality assessment scores are shown in Figure 2. Out of 11 points total, the average score across cohort studies was 8.0 (range 6-10). The score for the single case-control study was 8 out of 10 . The most frequent study limitations were insufficient follow-up time, a lack of strategies to describe and address incomplete follow-up, and a lack of appropriate statistical analyses.

All of the articles described used the term extensively drug-resistant TB, and its associated abbreviations. Two of the articles also utilized other terms and abbreviations to describe the highest levels of resistance in the patient population. ${ }^{57,65}$ Pietersen et al used the

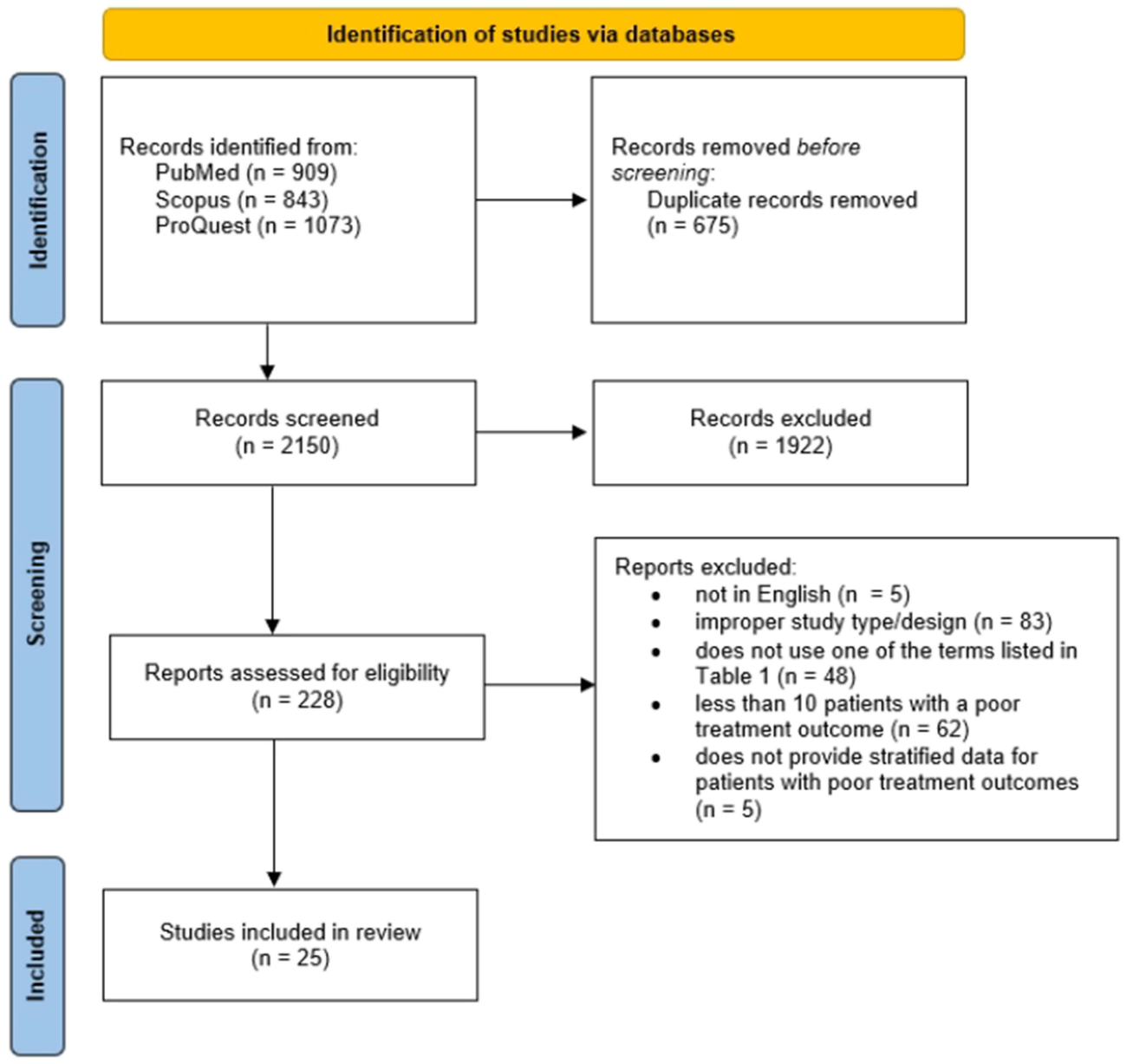

Figure I Study selection flow diagram.

Notes: PRISMAfigureadaptedfromPage MJ, McKenzie JE, Bossuyt PM, Boutron I, Hoffmann TC, Mulrow CD, et al. The PRISMA 2020 statement: an updated guideline for reporting systematic reviews. BMJ 2021;372:n7I.CreativeCommons. ${ }^{26}$ 


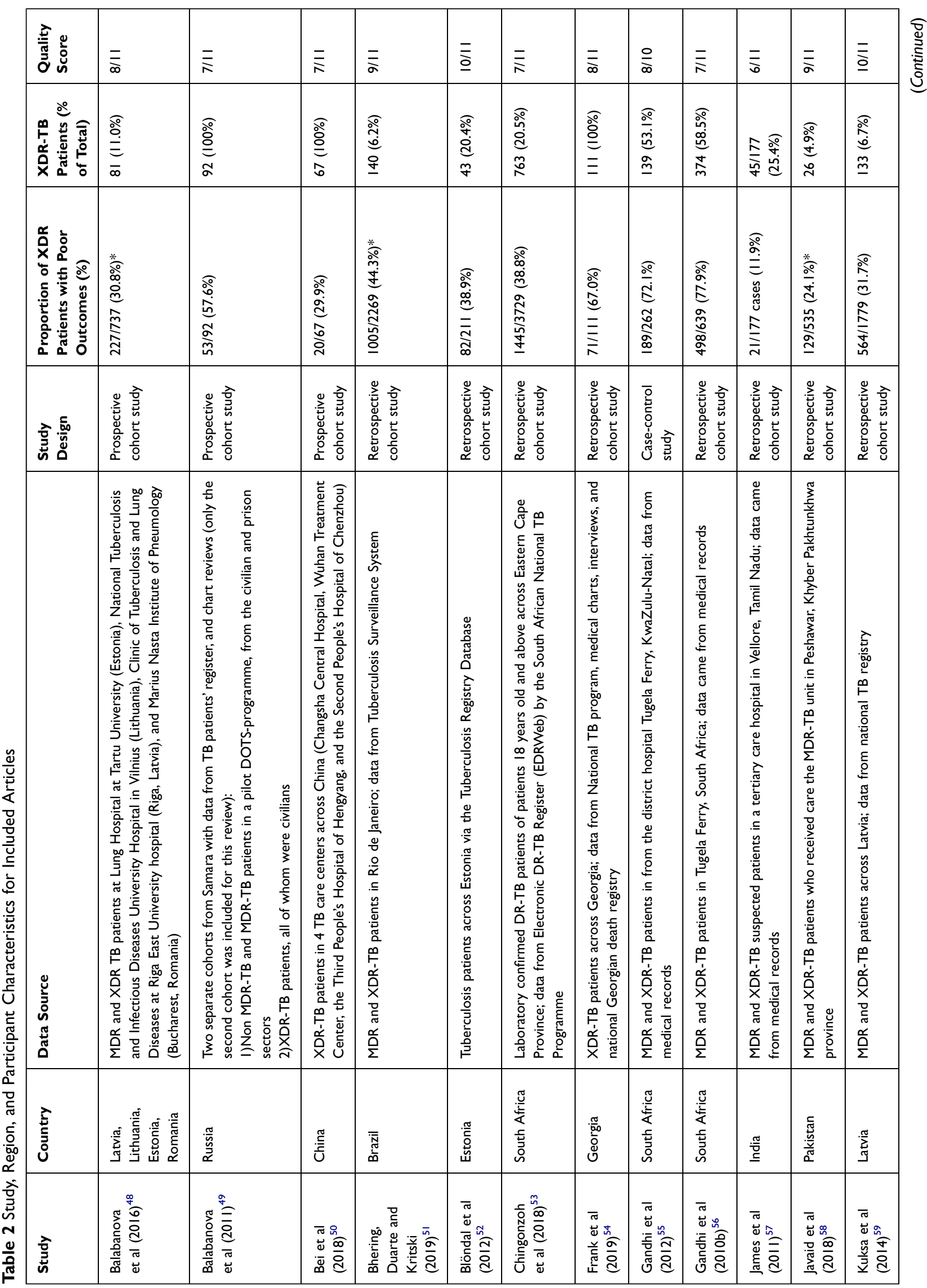




\begin{tabular}{|c|c|c|c|c|c|c|c|c|c|c|c|c|c|}
\hline 胥 & $\overline{\underline{ }}$ & $\overline{\bar{\infty}}$ & $\overline{\bar{\sigma}}$ & 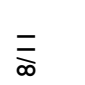 & $\overline{\bar{a}}$ & $\bar{亠}$ & $\bar{\Sigma}$ & $\bar{\Sigma}$ & $\bar{\Sigma}$ & $\bar{\Xi}$ & $\overline{\bar{\infty}}$ & 흐 & $\overline{\bar{z}}$ \\
\hline 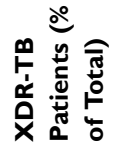 & 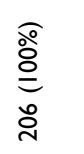 & 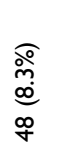 & 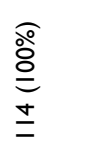 & $\begin{array}{l}\stackrel{\overparen{\circ}}{\stackrel{\circ}{\circ}} \\
\frac{\circ}{N}\end{array}$ & 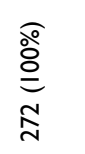 & 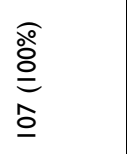 & 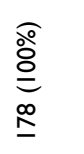 & $\underset{\substack{\stackrel{\circ}{\circ} \\
\stackrel{\circ}{\circ}}}{ }$ & 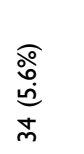 & 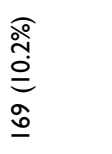 & $\frac{\stackrel{\circ}{\circ}}{\stackrel{\circ}{\circ}}$ & 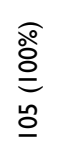 & 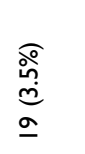 \\
\hline 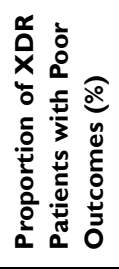 & 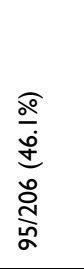 & 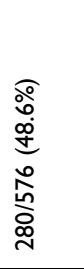 & 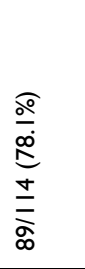 & $\begin{array}{l}\frac{0}{\hat{d}} \\
\text { ḋ } \\
\frac{0}{a} \\
\frac{a}{d}\end{array}$ & 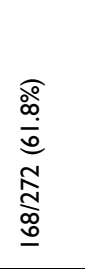 & 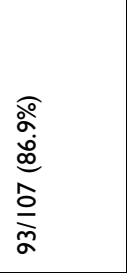 & 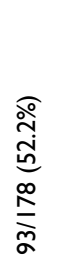 & 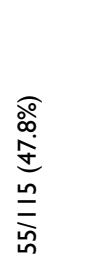 & 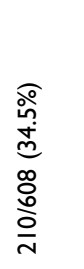 & 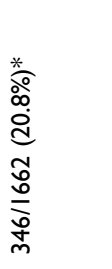 & 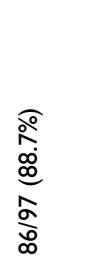 & 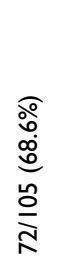 & 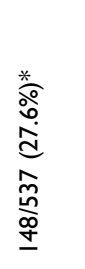 \\
\hline 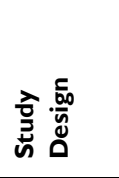 & 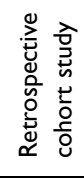 & 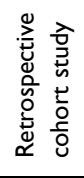 & 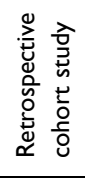 & 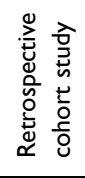 & 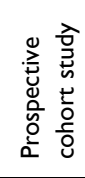 & 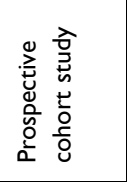 & 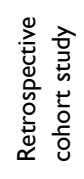 & 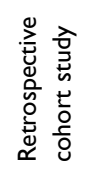 & 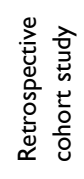 & 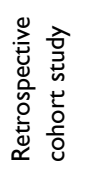 & 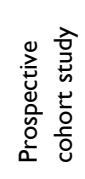 & 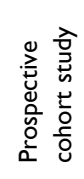 & 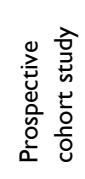 \\
\hline 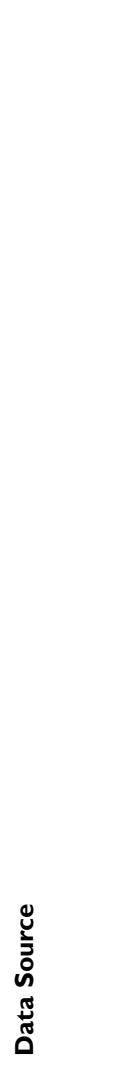 & 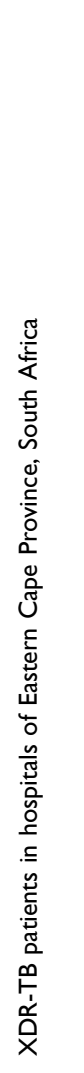 & 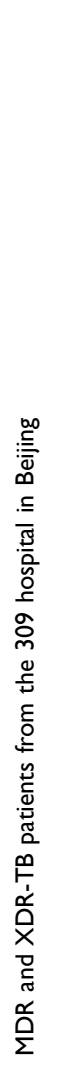 & 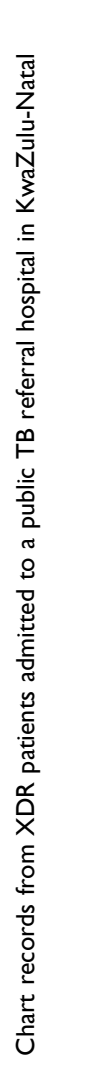 & 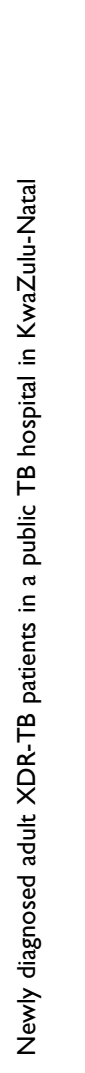 & 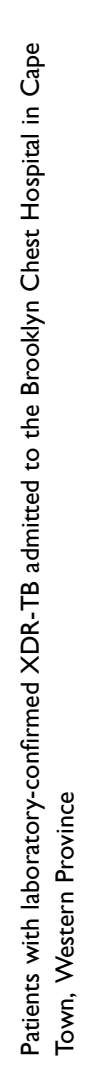 & 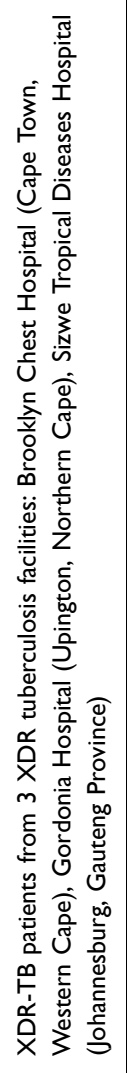 & 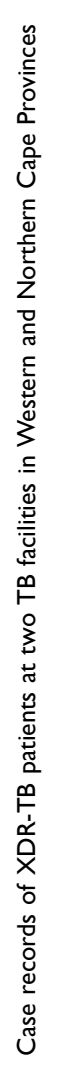 & 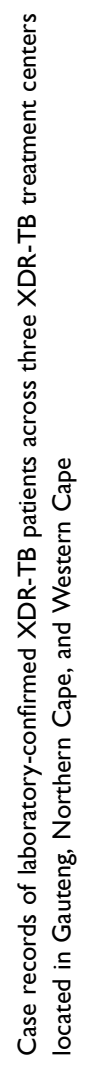 & 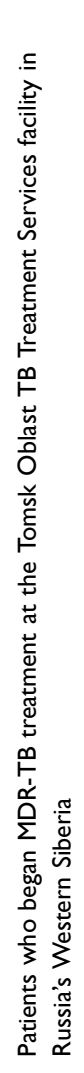 & 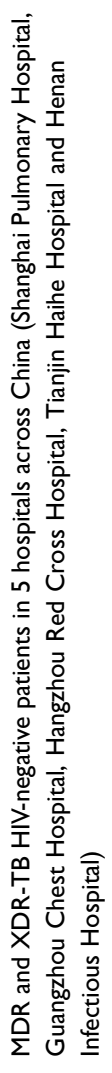 & 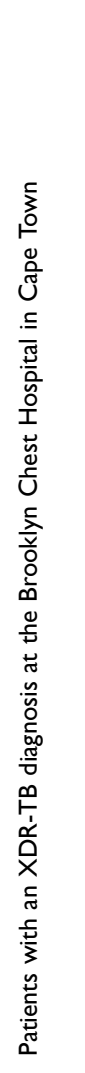 & 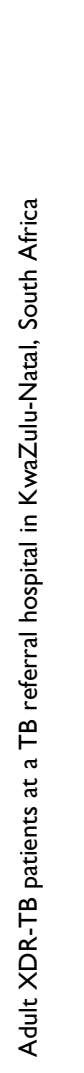 & 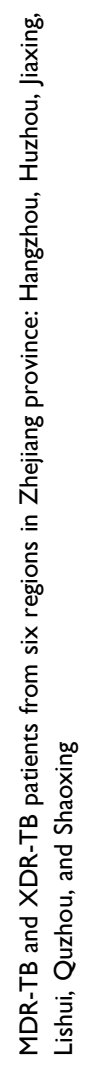 \\
\hline نे & 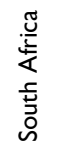 & 窇 & 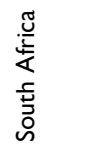 & 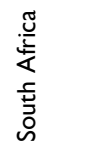 & 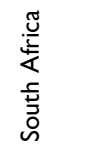 & 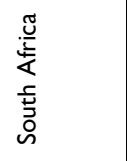 & 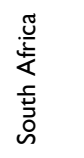 & 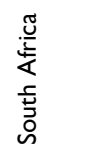 & 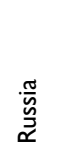 & 选 & 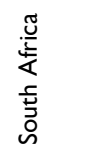 & 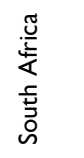 & $\frac{\tilde{\sigma}}{\tilde{E}}$ \\
\hline 离 & 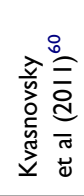 & 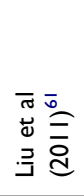 & 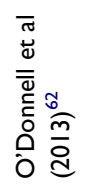 & 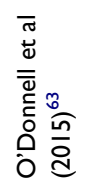 & 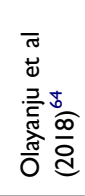 & 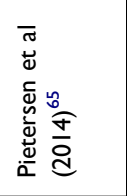 & 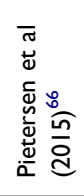 & 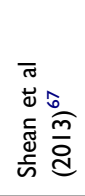 & 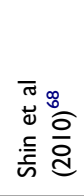 & 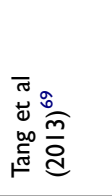 & 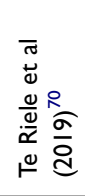 & 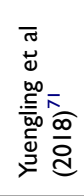 & 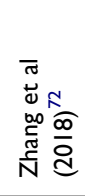 \\
\hline
\end{tabular}




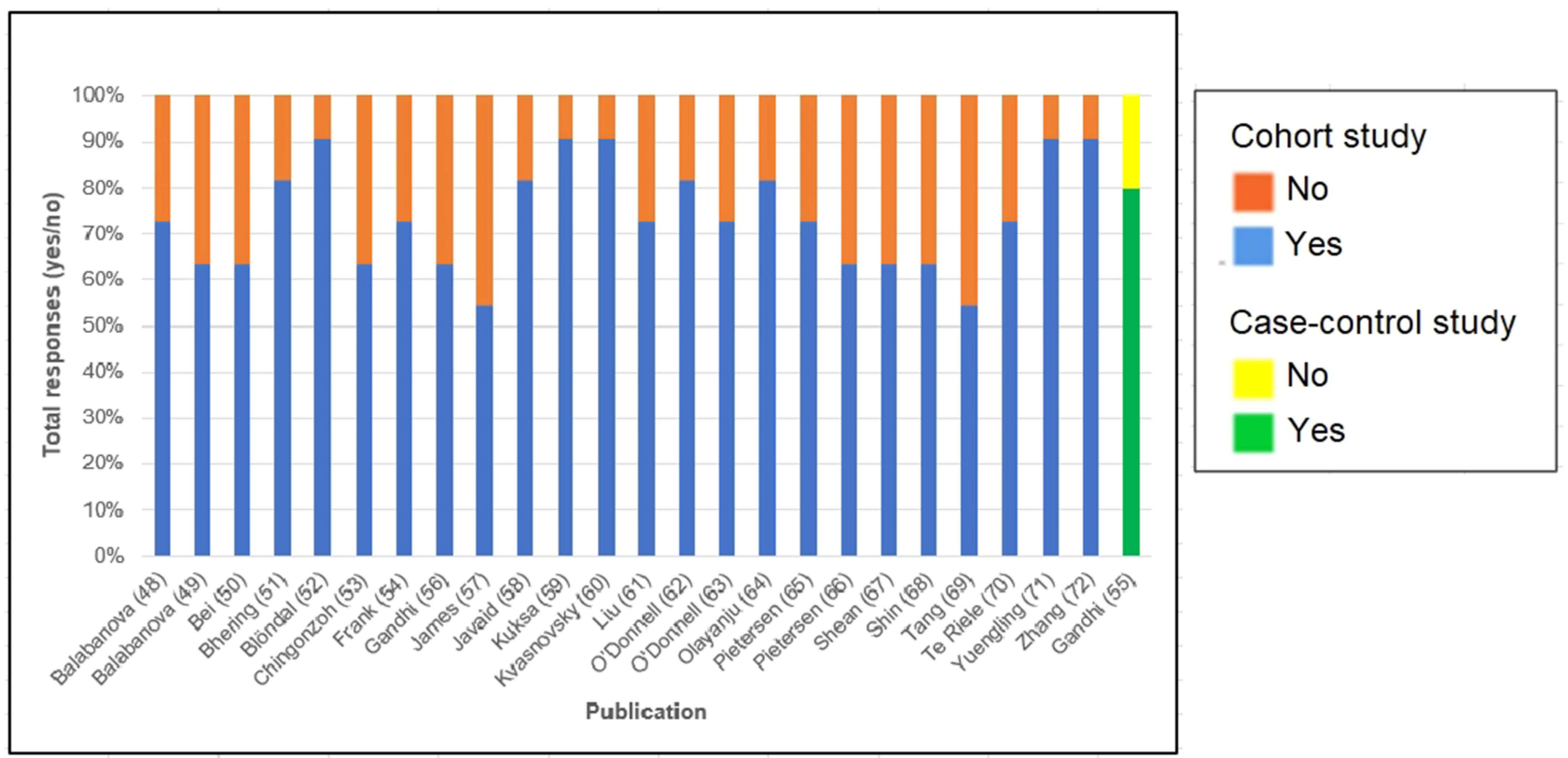

Figure 2 Quality assessment score by study with the Joanna Briggs Institute's Tools.

term totally drug-resistant $\mathrm{TB},{ }^{65}$ and James et al used TDR-TB and XXDR-TB. ${ }^{57}$

Table 3 lists the risk factors for poor outcomes among patients in the included studies. A history of TB was consistently found to increase risk of poor outcomes among XDR-TB patients. In a number of the studies reviewed, nearly all patients who had a poor outcome had been undergoing retreatment for TB after having previously failed treatment/defaulted treatment/been cured. One study found that $90.5 \%$ of patients with poor outcomes were retreatment cases. ${ }^{69}$ A different study found that $93.0 \%$ of patients with poor outcomes had a history of TB. ${ }^{68}$ In another study, all 45 patients with XDR-TB/ TDR-TB had a reported history of TB. ${ }^{57}$

Evidence from a wide array of contexts showed that the presence of HIV increases risk for poor outcomes, and in the three studies with the highest proportions of this comorbidity, $79.6 \%,{ }^{62} 82.7,{ }^{56}$ and $82.9 \%{ }^{55}$ of patients had both poor outcomes and HIV. The studies with the highest proportion of cases of HIV were from South Africa. The few studies that completed stratification based on whether patients were HIV-positive and were receiving antiretroviral therapies (ARTs) consistently found that risk of death was considerably higher among people with HIV who did not receive ARTs compared to those who did. ${ }^{56,60,64,71}$

Aside from HIV, findings related to comorbidities were limited. Eight of the 25 studies included an analysis of diseases/health issues other than HIV. $^{49-51,54,58,61,69,70}$
Comorbidities included in these studies were: diabetes,$51,54,61,69,70$ hepatitis, ${ }^{54,61,89}$ chronic obstructive pulmonary disease (COPD), ${ }^{61,69}$ abnormal liver function, ${ }^{61}$ low albumin, ${ }^{69}$ and hypertension. ${ }^{61}$ The total proportions of patients with comorbidities in these studies were generally relatively low, with the exception of two studies. ${ }^{54,69}$ In the first of these two studies, $26.8 \%$ of patients with poor outcomes had hepatitis $\mathrm{C}$ virus. $^{54}$ In the second study, $30.3 \%$ of patients with poor outcomes had low albumin levels, and $18.8 \%$ had diabetes. ${ }^{69}$

Findings related to age were mixed, although the majority of the studies that analyzed age as a potential risk factor showed that individuals approximately 30-45 years of age were at the highest risk for poor outcomes, ${ }^{48,53-56,58,59,61,70,71}$ or that differences among age groups were minimal. ${ }^{49,63-65,68}$ Studies that included patients under 18 years of age indicated that young patients comprise a relatively low proportion of patients with poor outcomes. ${ }^{48,58,59,61}$

In 15 of the 25 articles, men were more likely than women to be at risk for mortality, default, and/or treatment failure. $^{48-52,54,59-61,64,65,69-72}$ Some studies varied greatly in the number of men and women included, with several studies having a considerably higher proportion of male participants with poor outcomes, ${ }^{48,54,59,61,72}$ and others having considerably higher women. ${ }^{54,56,58,62}$

The studies identified a number of other risk factors. Alcohol abuse was described in three studies; ${ }^{54,59,68}$ and two of these studies each included individuals who were regular consumers of alcohol and had TB with poor 


\begin{tabular}{|c|c|c|c|}
\hline 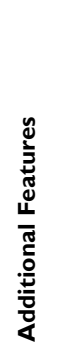 & 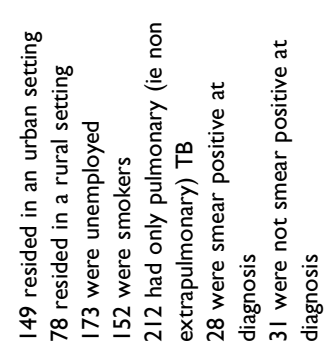 & & 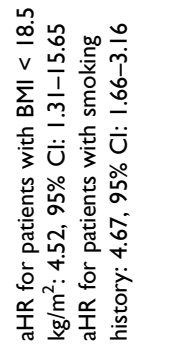 \\
\hline 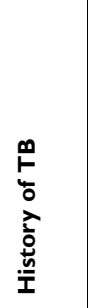 & 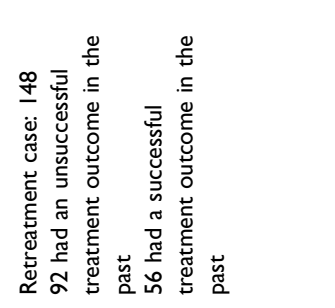 & 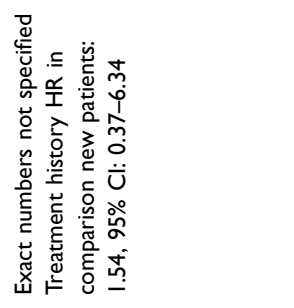 & 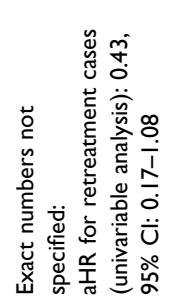 \\
\hline 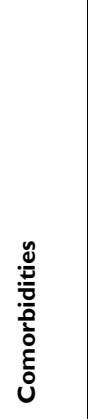 & 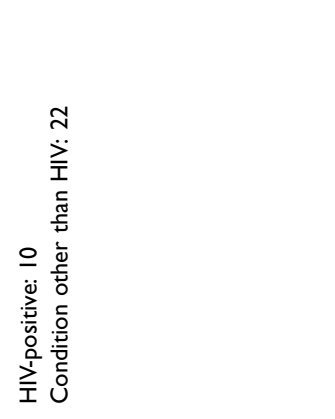 & 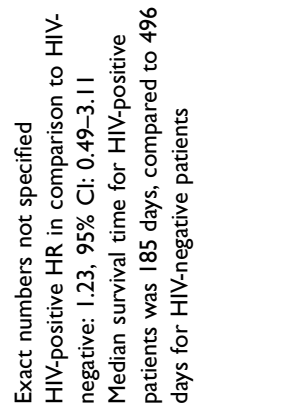 & 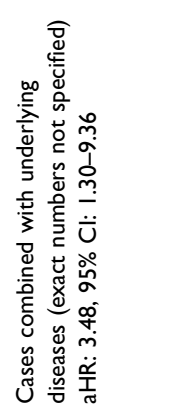 \\
\hline 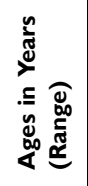 & 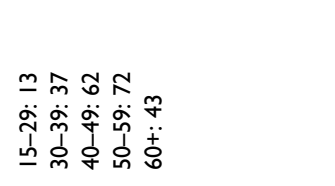 & 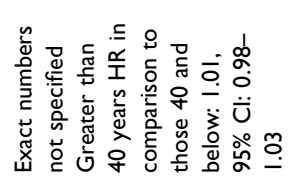 & 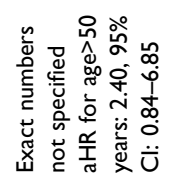 \\
\hline 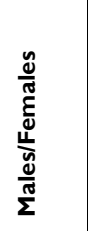 & 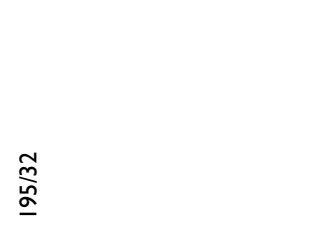 & 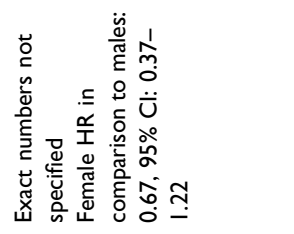 & 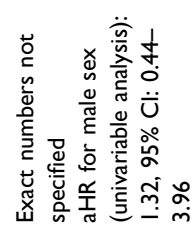 \\
\hline 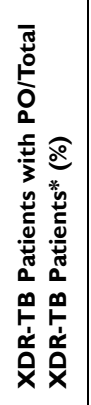 & 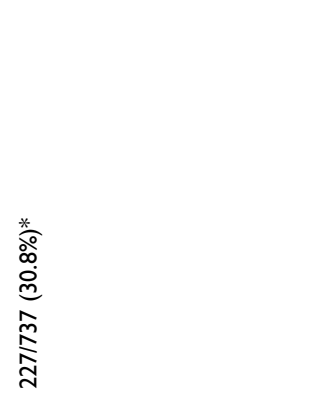 & 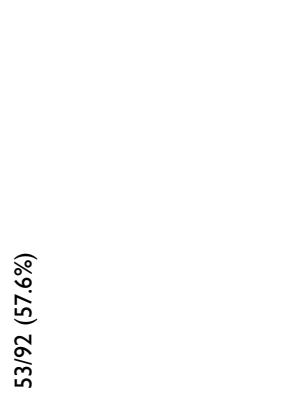 & 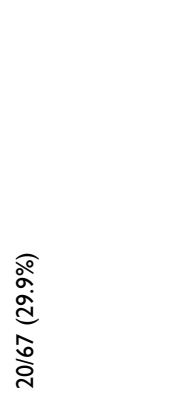 \\
\hline 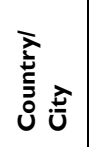 & 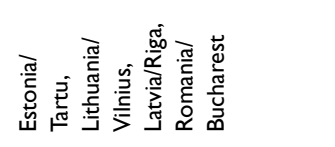 & 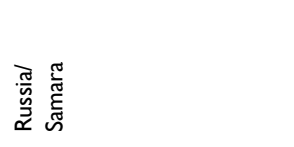 & 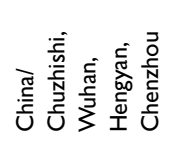 \\
\hline $\begin{array}{l}\text { 홀 } \\
\text { ज़ }\end{array}$ & 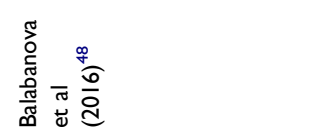 & 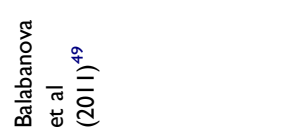 & 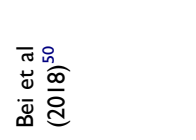 \\
\hline
\end{tabular}




\begin{tabular}{|c|c|c|c|}
\hline 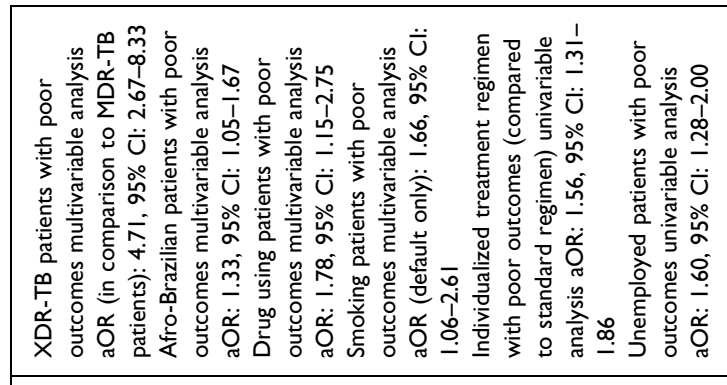 & 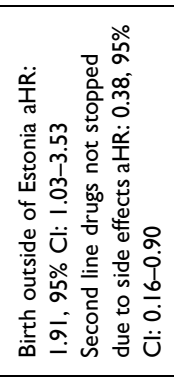 & 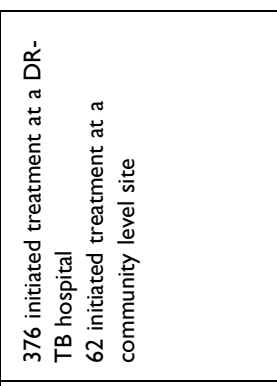 & 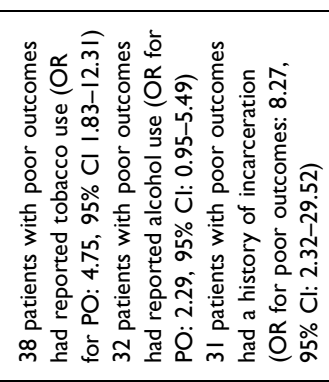 \\
\hline 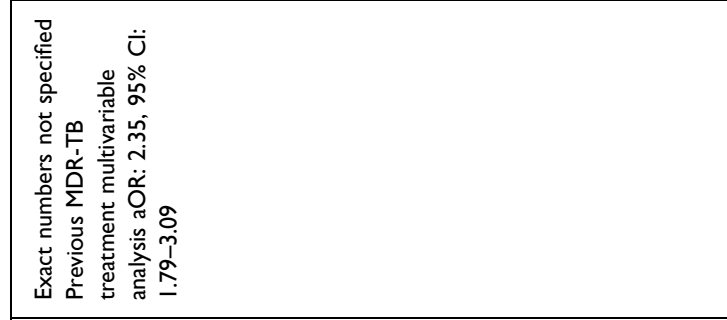 & 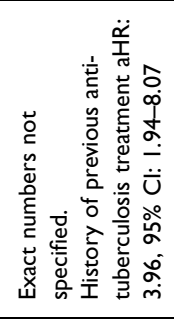 & 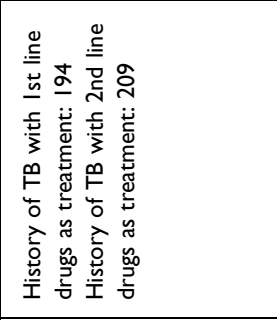 & $\bar{F}$ \\
\hline 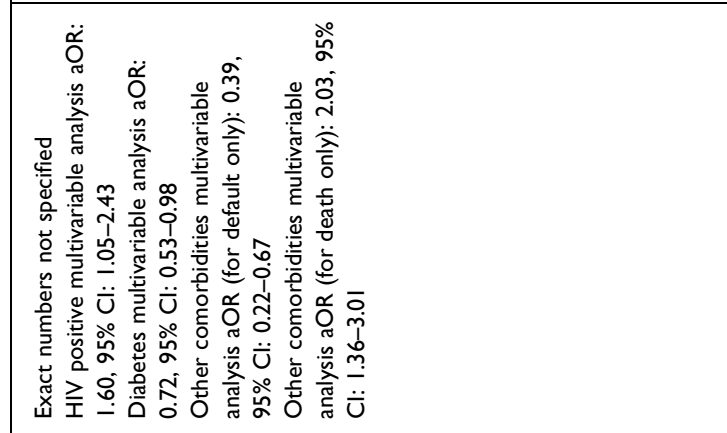 & & 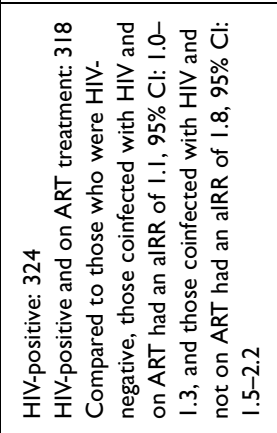 & 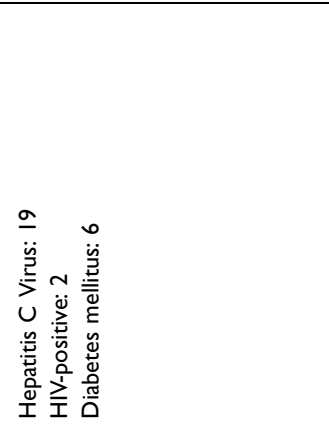 \\
\hline 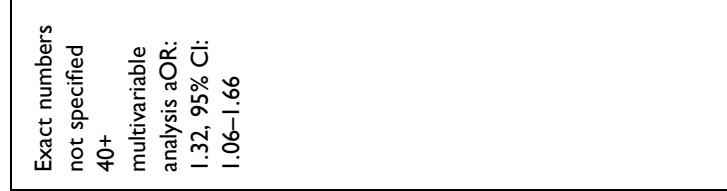 & 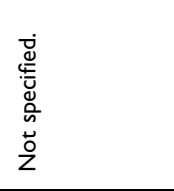 & 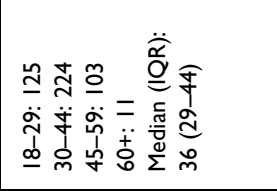 & 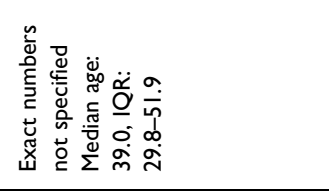 \\
\hline 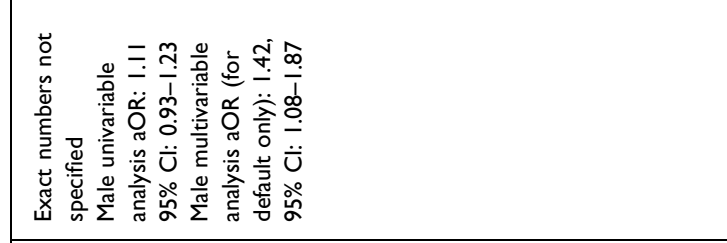 & 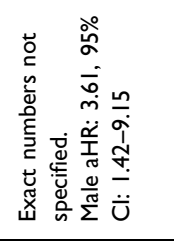 & 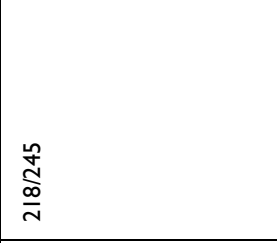 & 瓷 \\
\hline 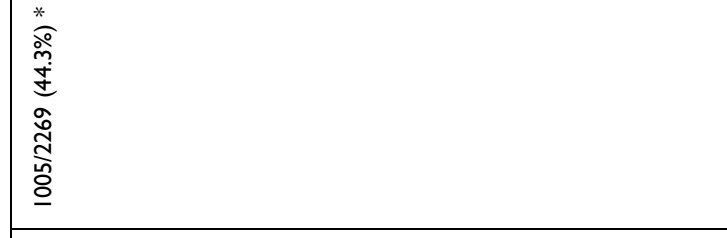 & 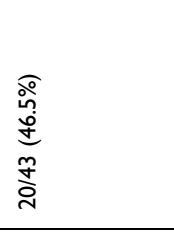 & 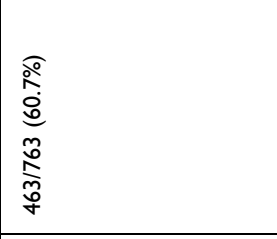 & 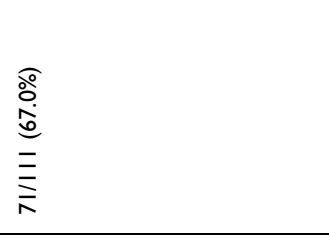 \\
\hline 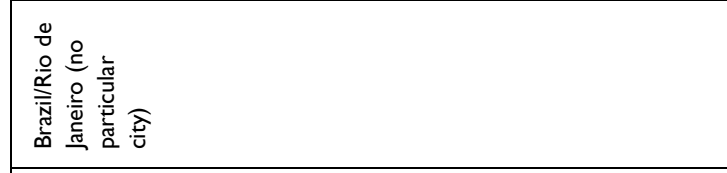 & 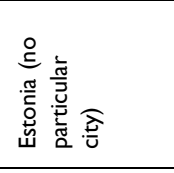 & 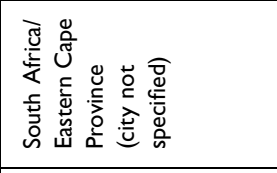 & 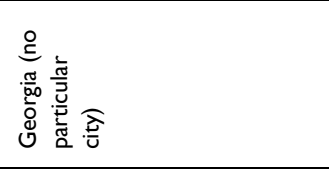 \\
\hline 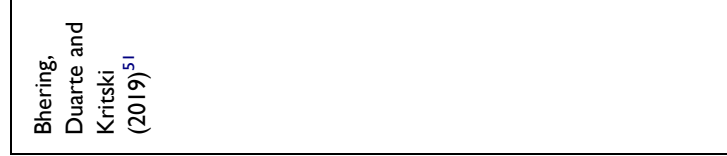 & 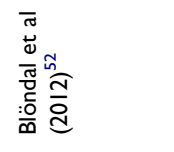 & 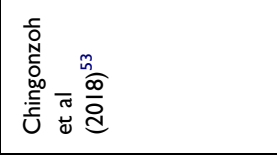 & 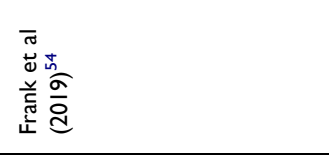 \\
\hline
\end{tabular}




\begin{tabular}{|c|c|c|c|c|}
\hline 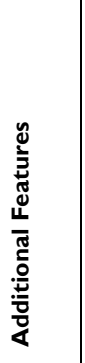 & 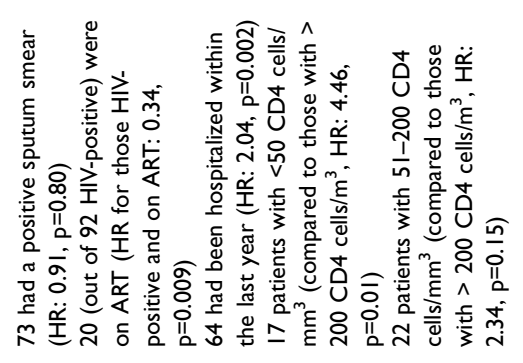 & 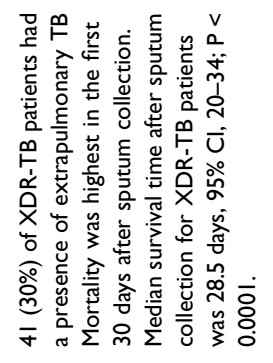 & 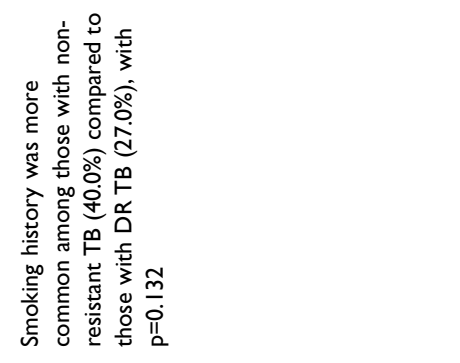 & 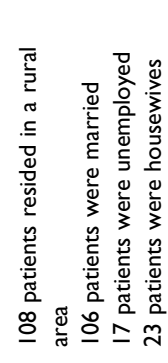 \\
\hline 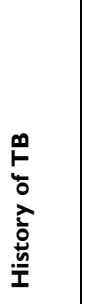 & 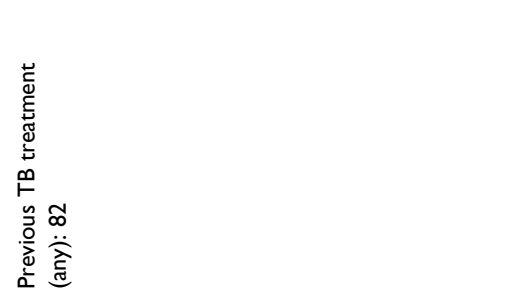 & 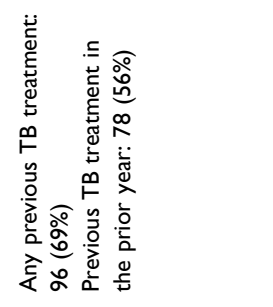 & 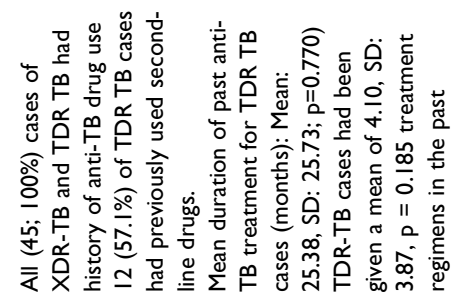 & 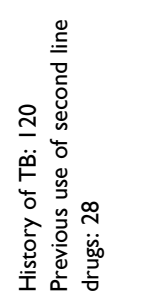 \\
\hline 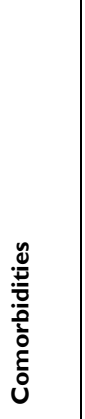 & 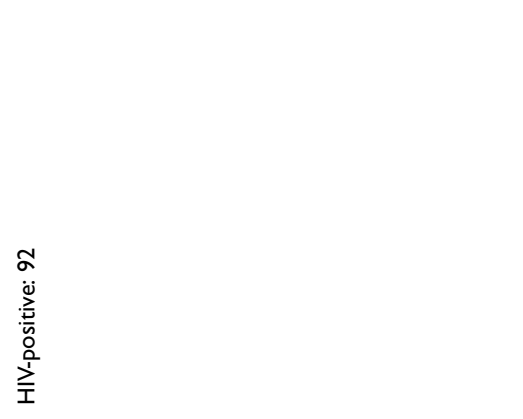 & 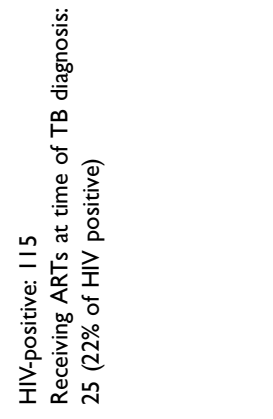 & 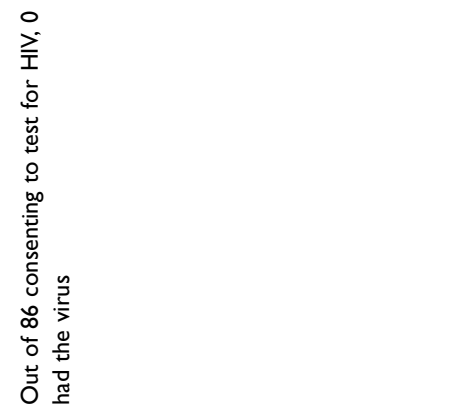 & 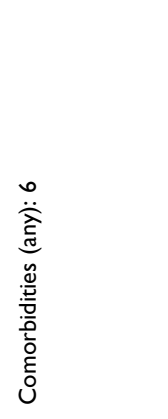 \\
\hline 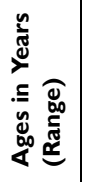 & 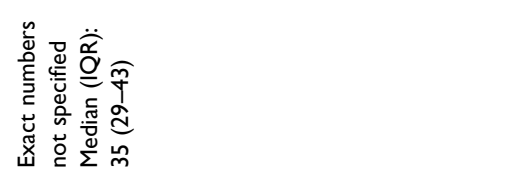 & 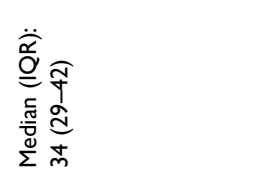 & 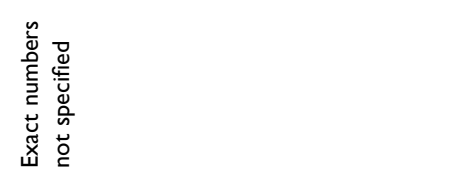 & 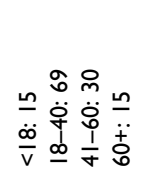 \\
\hline 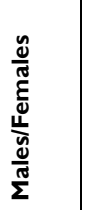 & 总 & $\stackrel{\infty}{\stackrel{\infty}{\omega}}$ & 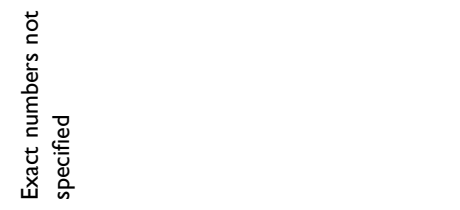 & స్ \\
\hline 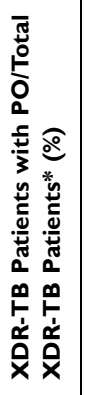 & 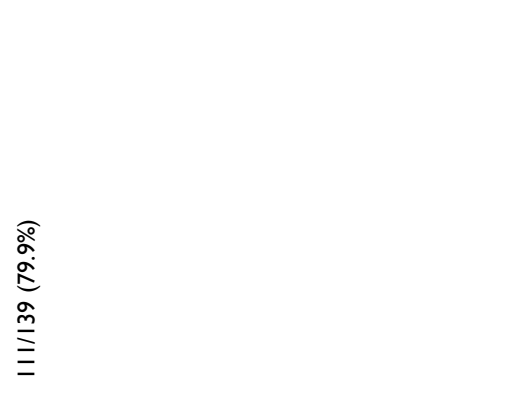 & 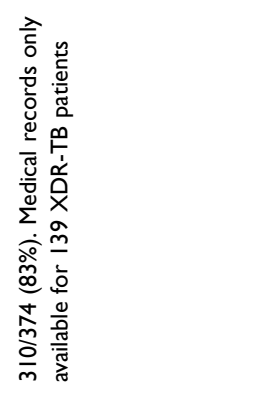 & 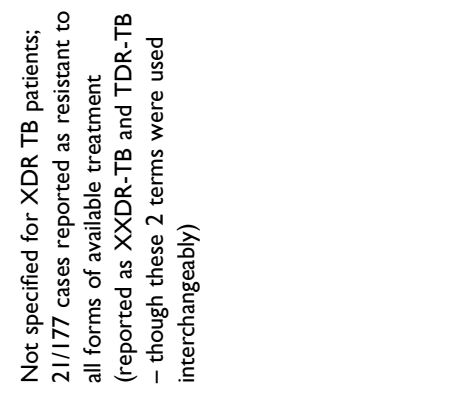 & 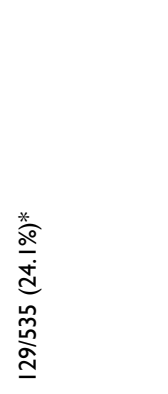 \\
\hline 就 & 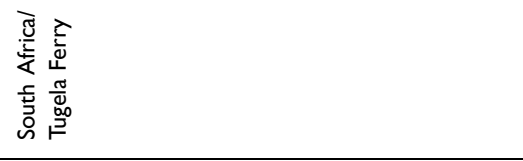 & 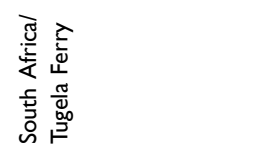 & 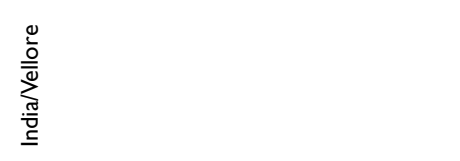 & 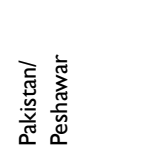 \\
\hline 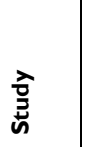 & 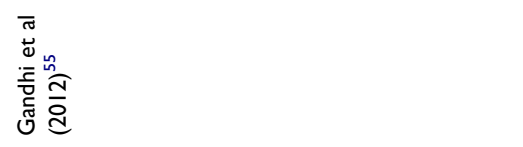 & 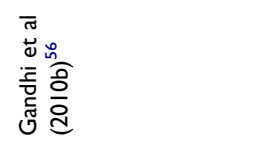 & 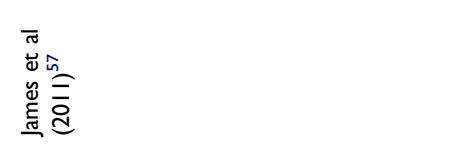 & 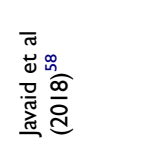 \\
\hline
\end{tabular}




\begin{tabular}{|c|c|c|}
\hline 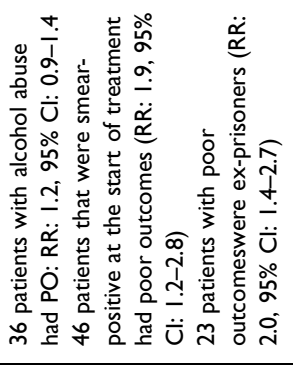 & 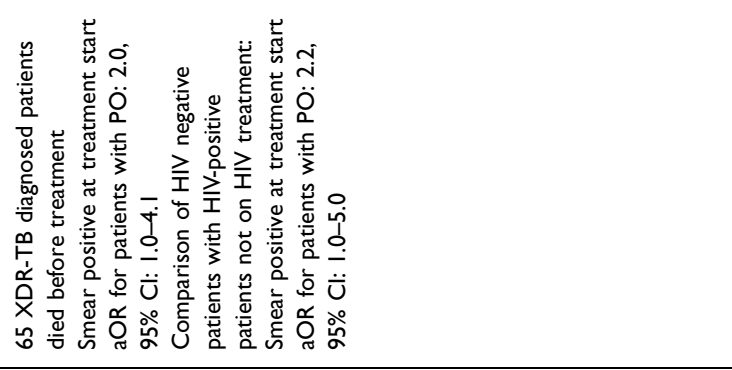 & 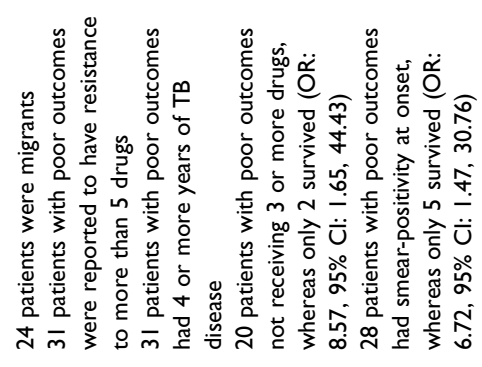 \\
\hline 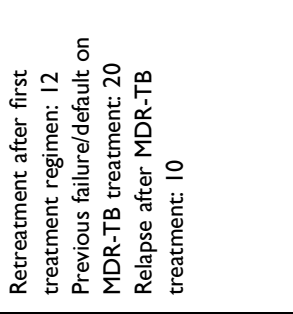 & 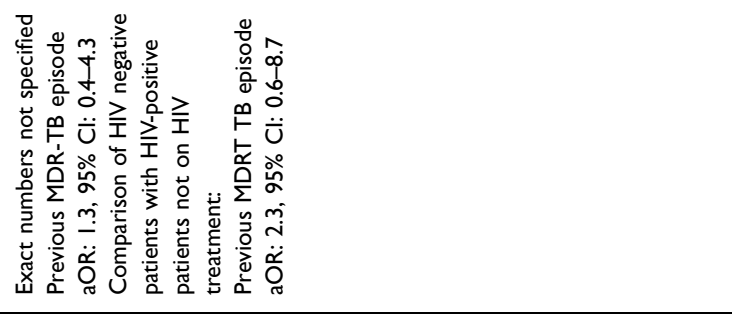 & $\stackrel{\sim}{\sim}$ \\
\hline & 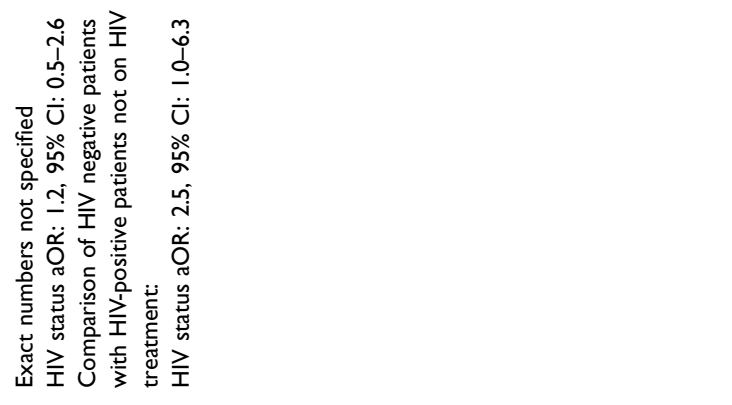 & 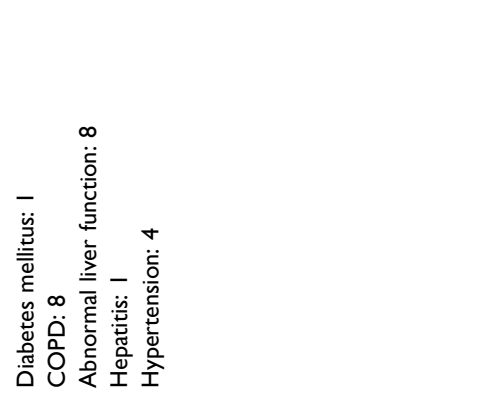 \\
\hline 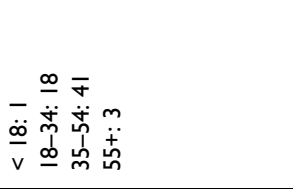 & 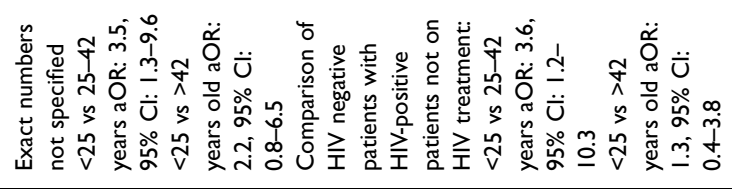 & 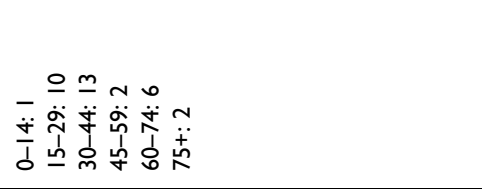 \\
\hline$\stackrel{\frac{n}{\infty}}{\dot{w}}$ & 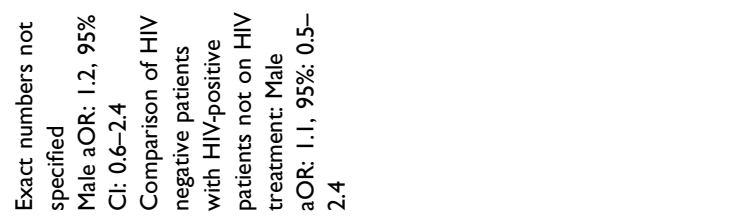 & $\stackrel{\infty}{\infty}$ \\
\hline 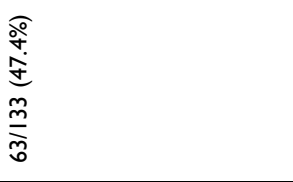 & 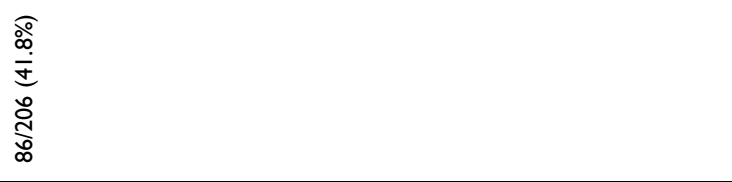 & 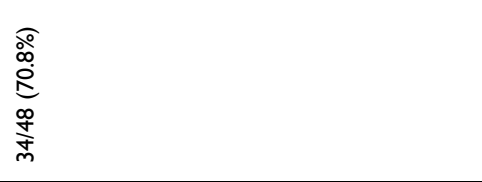 \\
\hline 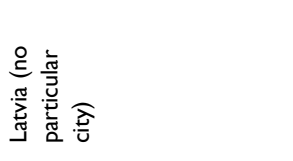 & 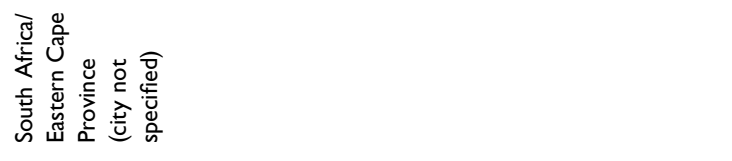 & 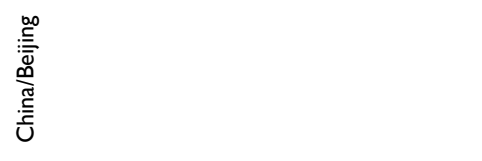 \\
\hline 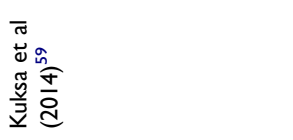 & 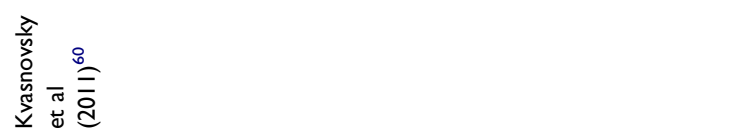 & 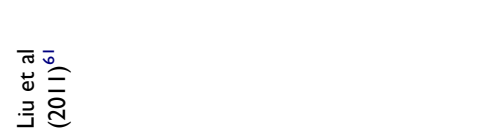 \\
\hline
\end{tabular}




\begin{tabular}{|c|c|c|c|c|c|}
\hline 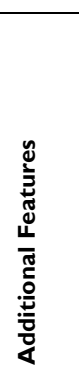 & 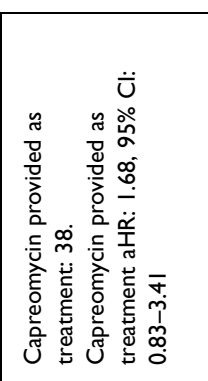 & 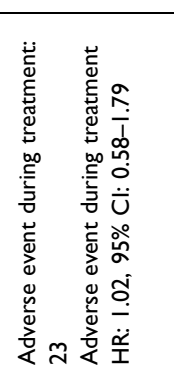 & 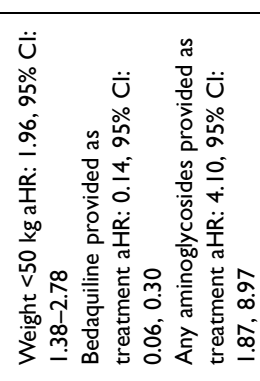 & 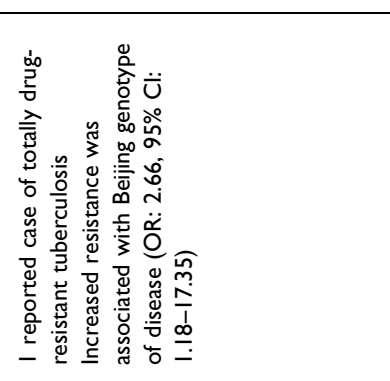 & 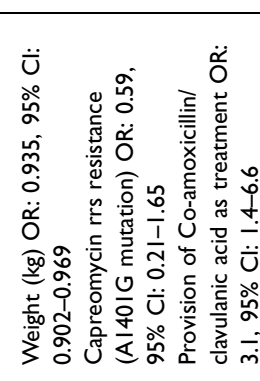 \\
\hline 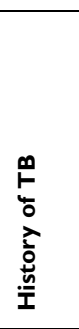 & 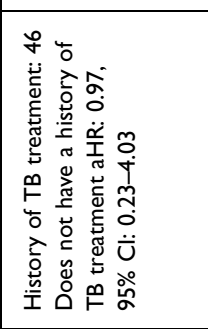 & 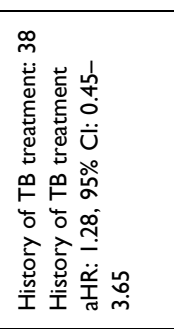 & 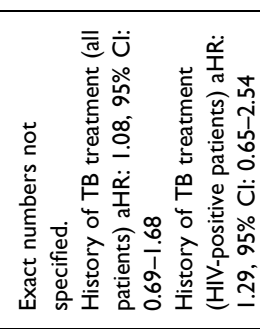 & 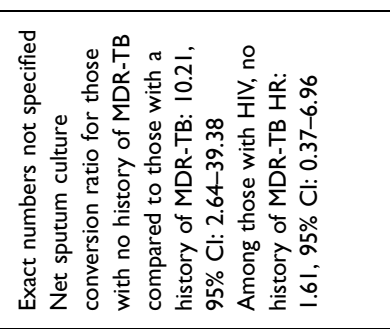 & 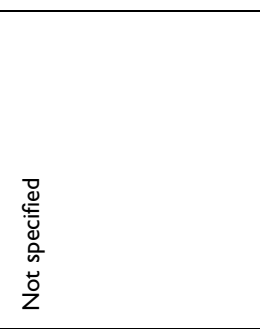 \\
\hline 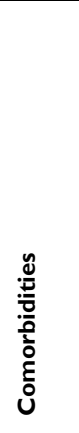 & 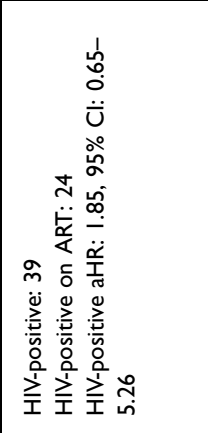 & 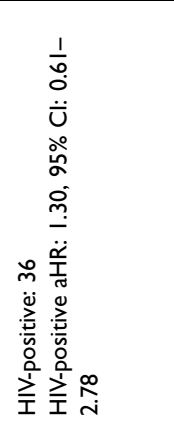 & 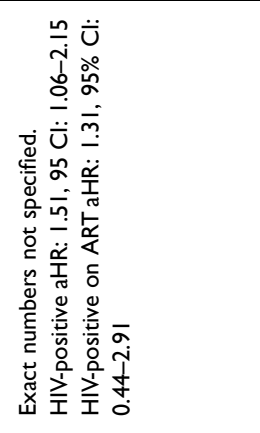 & 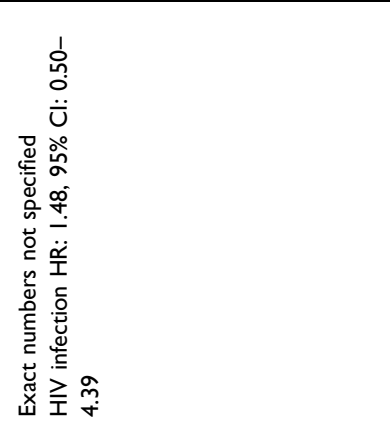 & 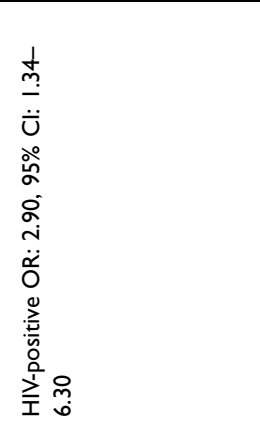 \\
\hline 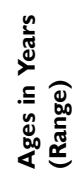 & 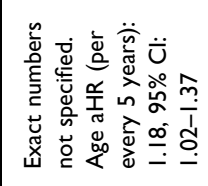 & 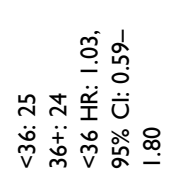 & 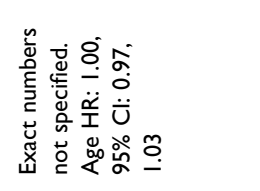 & 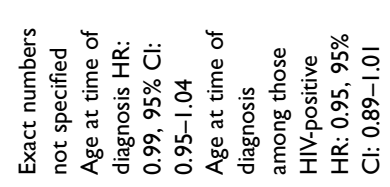 & 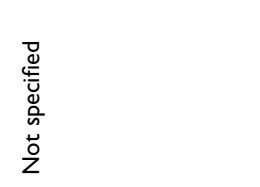 \\
\hline 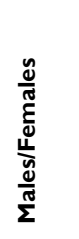 & 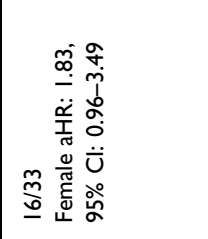 & 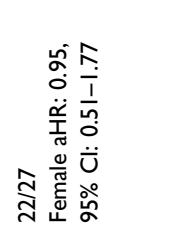 & 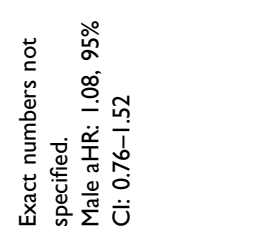 & 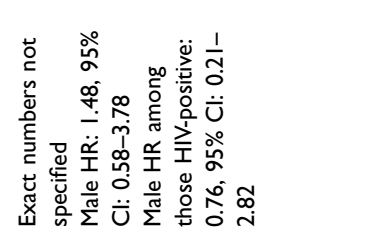 & 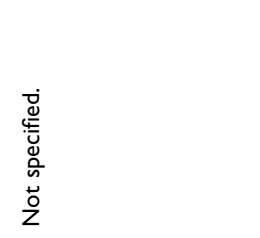 \\
\hline 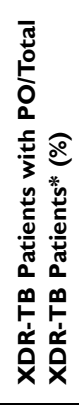 & 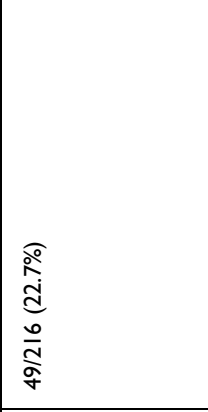 & 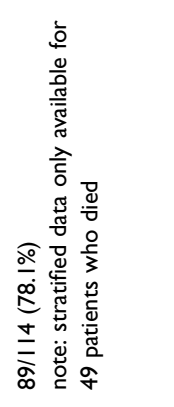 & 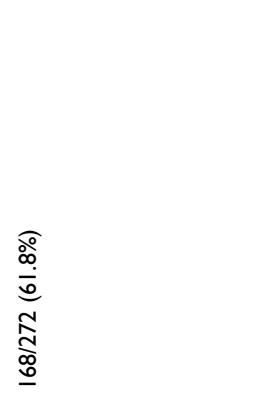 & 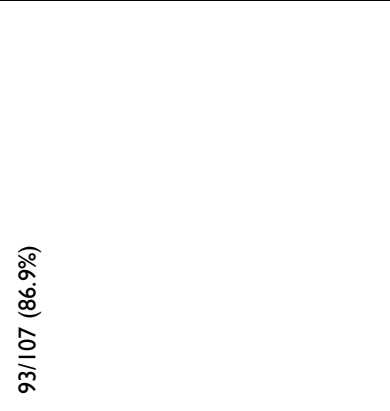 & 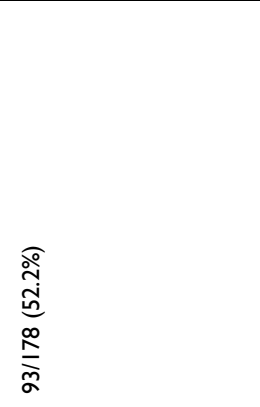 \\
\hline 童 & 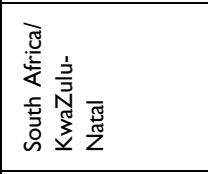 & 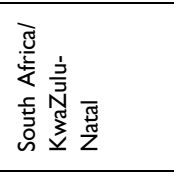 & 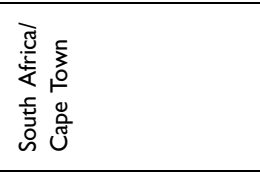 & 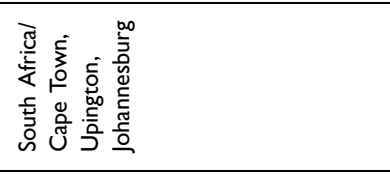 & 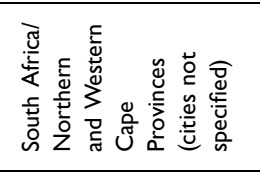 \\
\hline$\stackrel{\vec{z}}{\vec{y}}$ & 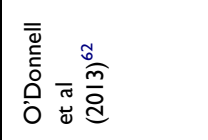 & 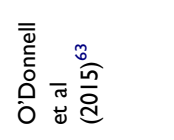 & 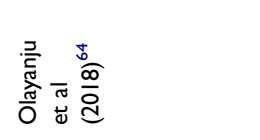 & 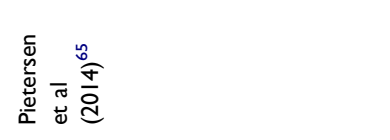 & 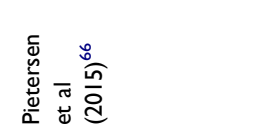 \\
\hline
\end{tabular}




\begin{tabular}{|c|c|c|c|c|}
\hline 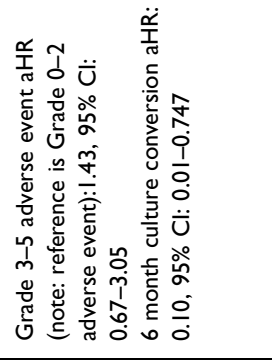 & 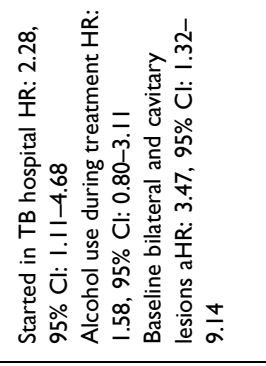 & 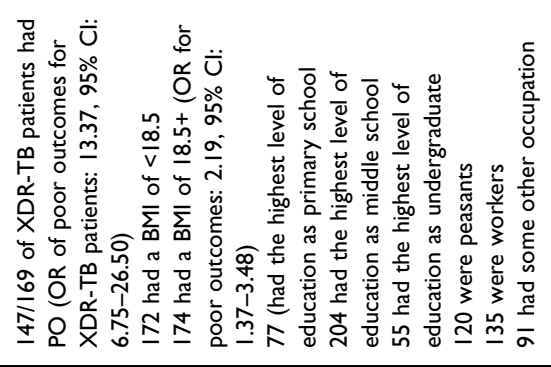 & 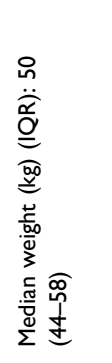 & 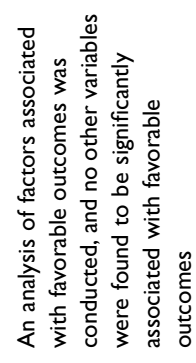 \\
\hline 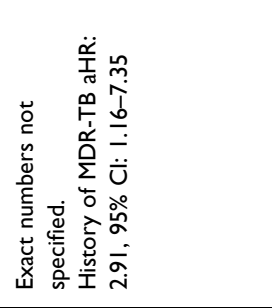 & 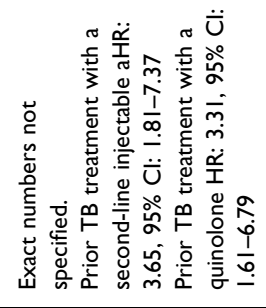 & 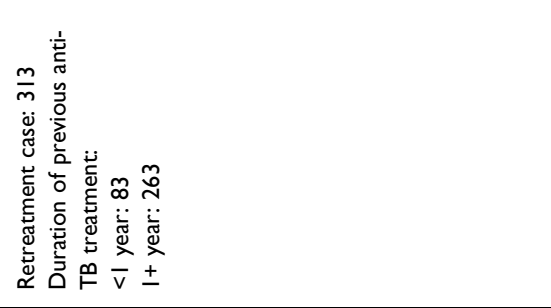 & 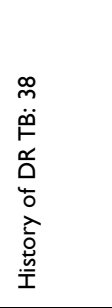 & 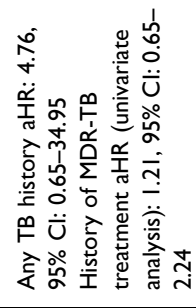 \\
\hline 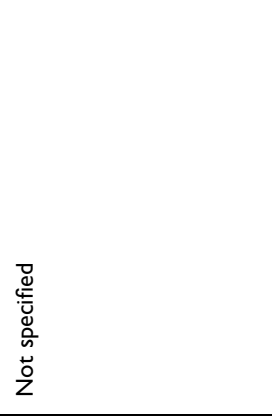 & 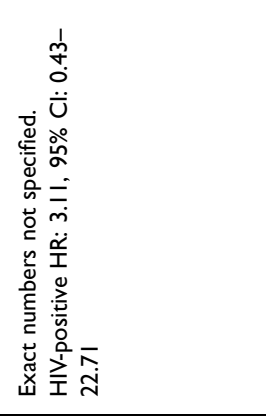 & 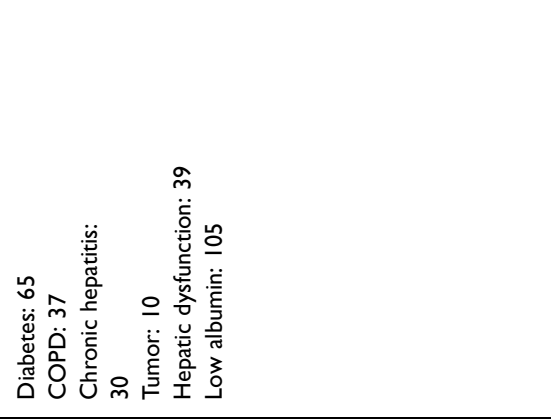 & 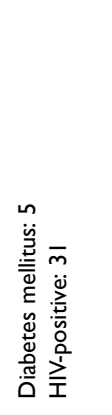 & 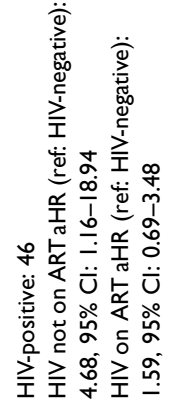 \\
\hline 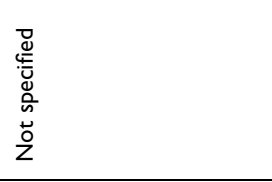 & 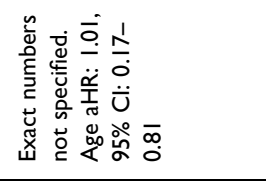 & 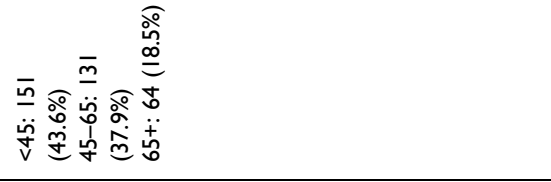 & 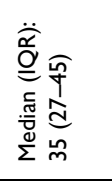 & 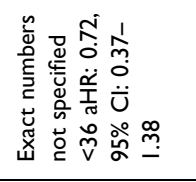 \\
\hline 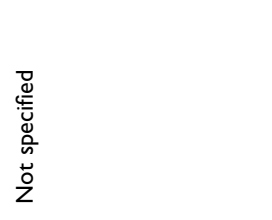 & 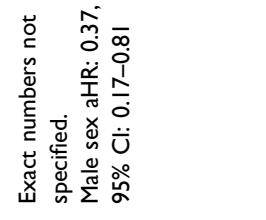 & 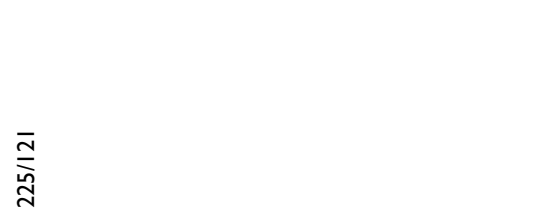 & 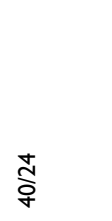 & 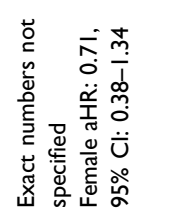 \\
\hline 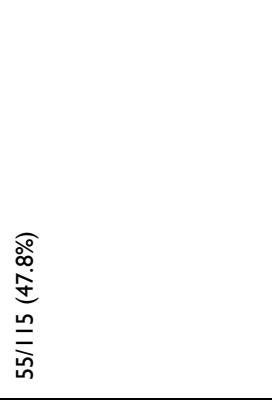 & 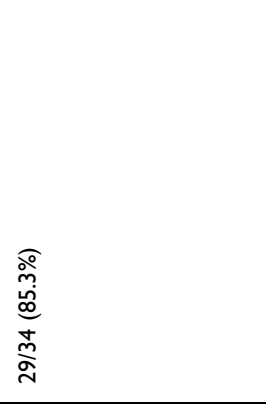 & 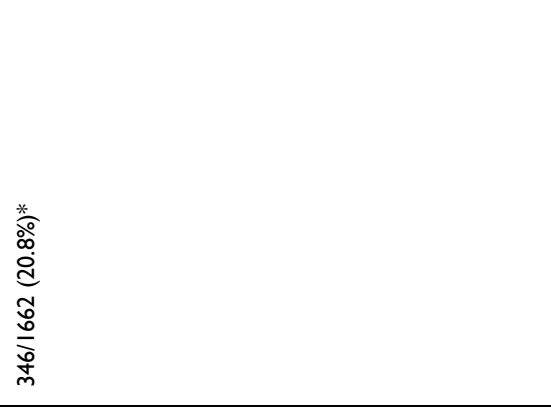 & 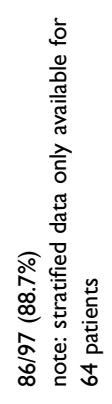 & 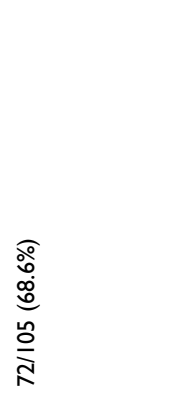 \\
\hline 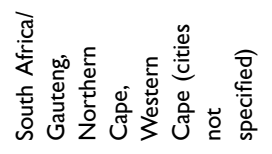 & 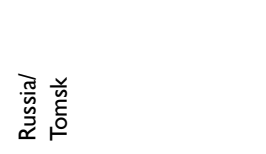 & 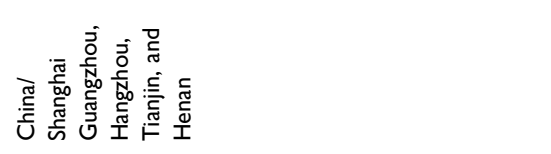 & 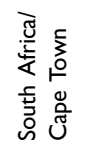 & 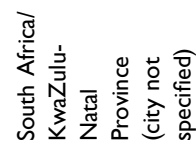 \\
\hline 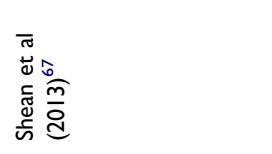 & 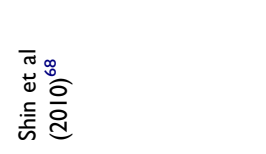 & 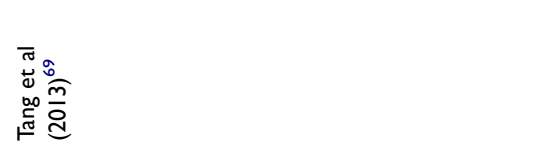 & 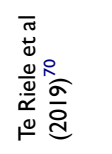 & 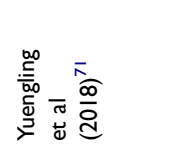 \\
\hline
\end{tabular}




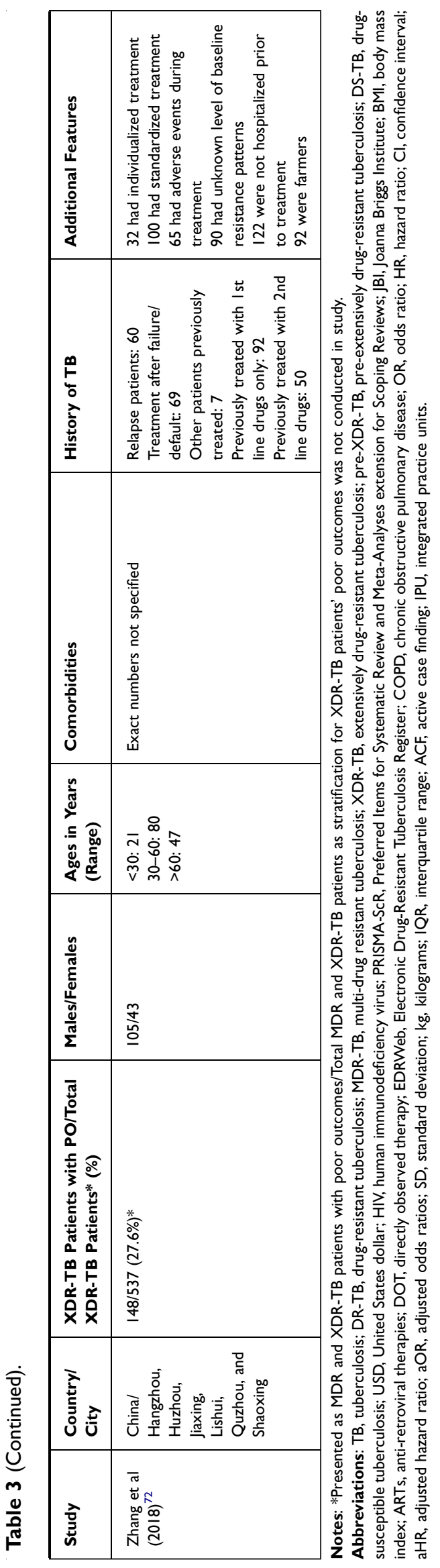

outcomes. ${ }^{54,59}$ A history of smoking was reported in four studies. ${ }^{50,51,54,57}$ In one of these studies, individuals with a smoking history had an adjusted hazard ratio of 4.67 (95\% CI: 1.66-13.16) in comparison to those who had never smoked. ${ }^{50}$ Another study had fairly similar results, with smokers having an odds ratio (OR) for poor outcomes of 4.75 (95\% CI: $1.83-12.31){ }^{54}$ Two studies analyzed history of incarceration as a risk factor, and in both of these studies, former prisoners had higher odds for poor outcomes compared to those who were not former prisoners. ${ }^{54,59}$ In one of these studies, former prisoners had a relative risk of $2.0(95 \%$ CI: $1.4-2.7),{ }^{59}$ and in the other study, former prisoners had an OR of 8.27 (95\% CI: 2.32-29.52). ${ }^{54}$ In two studies, low body mass was associated with higher odds of poor outcomes. ${ }^{50,69}$ The adjusted hazards ratio for patients of a BMI less than $18.5 \mathrm{~kg} / \mathrm{m}^{2}$ in a study involving 20 patients with poor outcomes was $4.52(95 \% \mathrm{CI}: 1.31-15.65),{ }^{50}$ and the OR in another was 2.19 (95\% CI: 1.37-3.48). ${ }^{69}$

Although socioeconomic status was not directly analyzed as a risk factor in any of the 25 studies reviewed, several studies did analyze other measures related to socioeconomic status. In one study, $76.2 \%$ were unemployed, ${ }^{48}$ and in another $13.2 \%$ were unemployed. ${ }^{58} \mathrm{~A}$ third study showed that unemployed patients had 1.60 odds of poor outcomes compared to those who were employed $(95 \%$ CI: $1.28-2.00) .{ }^{51}$ One study analyzed educational attainment and found that $22.2 \%$ of patients with poor outcomes had primary school as their highest level of education and $59.2 \%$ with poor outcomes had middle school as their highest level of education. ${ }^{69}$

Various other factors associated with poor outcomes that emerged in individual studies included having extrapulmonary $\mathrm{TB},{ }^{56}$ being a migrant,${ }^{52,61}$ having a Beijing genotype of disease, ${ }^{65}$ being treated with clavulanic acid, ${ }^{66}$ residing in a rural area, ${ }^{48,58}$ being of African descent, ${ }^{51}$ illicit drug-use, ${ }^{51}$ having had adverse reactions to $\mathrm{TB}$ treatment, ${ }^{52,63,67,72}$ being a farmer, ${ }^{72}$ and initiating treatment at a hospital rather than a community-level site. ${ }^{53,68}$ Based on the limited evidence, it was not possible to determine if these were risk factors XDR-TB.

\section{Discussion}

While at least 123 countries across the globe have reported the existence of XDR-TB, ${ }^{80}$ the majority of the studies in this review (16 of the 25 studies) were conducted either in South Africa or China. Globally, approximately half of the cases of MDR-TB occur in India, Russia, and China and XDR-TB was reported to be prevalent in India as far back 
as in $2012 .{ }^{13,81}$ However, only one study from India, ${ }^{57}$ and two from Russia ${ }^{49,68}$ were eligible for this review. It is therefore strongly recommended that more studies be conducted in India and Russia on risk factors for poor outcomes of XDR-TB.

In our review, it was found that a number of different factors have been shown to increase the risk for poor outcomes among XDR-TB patients. These include a previous history of $\mathrm{TB}$, alcoholism, smoking, low BMI, unemployment, as well as being male, formerly incarcerated, and middle-aged.

Our review has also shown that certain comorbidities consistently increase the risk for poor outcomes by XDRTB. In particular, HIV appears to be a risk factor, especially when untreated. These findings may explain why many of the studies included in this review were from South Africa, a country with the highest number of people living with HIV in the world. ${ }^{79}$ It is also plausible that socioeconomic status and quality of care served as confounders in this relationship, though these factors were infrequently analyzed in the studies included in this review. A number of studies in this review also showed evidence that diabetes is a risk factor for poor outcomes among XDR-TB patients. $51,54,61,69,70$

There are notable similarities between the findings of our review, and those of prior reviews on risk factors for mortality from other forms of DR-TB, as well as DS-TB. While previous reviews on DS-TB have had conflicting findings, ${ }^{82,83}$ HIV with advanced immunosuppression, non-infective comorbidities, alcohol use, and substance misuse have been identified as possible risk factors for mortality among DS-TB patients. ${ }^{82,83}$ Furthermore, similar to our findings, a previous review by Alemu et $\mathrm{al}^{24}$ showed that, among DR-TB patients, risk factors for mortality included being male, having HIV, clinical complications, and having diabetes or any other comorbidity.

Considering the risk for poor outcomes of coinfected HIV-positive patients, regardless of the level of drug-resistance, there is a clear need to focus on increasing access to care among this demographic. Settings that are endemic with both TB and HIV will require scaling up of resources to ensure that patients are treated for both diseases concurrently. As well, any type of comorbidity increases a TB patient's risk for poor outcomes at all levels of drugresistance, and this may be because TB both increases risk for other comorbidities and complicates management of pre-existing conditions. ${ }^{84}$ This further emphasizes the importance of ongoing efforts, such as the World Health
Organization's End TB strategy, to focus on management of comorbidities among TB patients. ${ }^{84}$ We hence recommend that future research be conducted on the possible relationship between XDR-TB and HIV, as well as diabetes and other comorbidities.

In contrast with previous reviews on risk factors for $\mathrm{TB}$ mortality, ${ }^{24,82,83}$ our review showed that there is strong evidence indicating that a previous history of TB is a risk factor for poor outcomes. Notably, all 25 studies reviewed included a proportion of individuals who previously underwent treatment for TB and died as a result of XDR-TB infection. While previous reviews on TB mortality have shown that, as age increases, risk for death also increases, ${ }^{24,82,83}$ our review instead demonstrated that those most commonly aged $30-45$ were at a greater risk. Former prisoners, smokers, those with low BMI, and those with COPD were found to be at an elevated risk for poor outcomes in our review, which was not shown to be the case for patients with DS-TB/other forms of DR-TB in previous reviews. ${ }^{24,82,83}$

As rates of poor outcomes among XDR-TB patients were shown to be exceedingly high in a number of included studies, it is important to consider the risk factors for developing XDR-TB alongside risk factors for XDRTB poor outcomes. In their systematic review on factors for developing XDR-TB, Flor de lima and Tavares ${ }^{15}$ found that previous TB treatment, prior TB treatment length, having had pre-XDR-TB in the past, being an immigrant, alcoholism, HIV co-infection, and being male all served as major risk factors. It was also found that XDR-TB was less likely to occur in older individuals, and there was limited evidence that being a prisoner, having had cancer, or diabetes increased risk. ${ }^{15}$

Our findings show that there are numerous important similarities between risk for developing XDR-TB, and for having poor outcomes. Therefore, it is critical that health interventions which focus on addressing outcomes for XDR-TB patients also concurrently prioritize preventative efforts against XDR-TB. The exceedingly high rates of poor outcomes among XDR-TB patients further highlights this importance.

The consistency of the finding that prior treatment of TB contributes to risk of both to developing XDR-TB, and to having poor outcomes with XDR-TB, highlights the need for efforts to ensure that patients consistently adhere to treatment. To date, efforts to improve adherence have focused on directly observed therapy (DOT) and DOT Plus for DR-TB. These programs are effective in ensuring 
that patients complete their treatment regimens, and they need to be continued and potentially scaled up. However, these programs may not be enough to reduce escalation of XDR-TB.

In order to address issues of patient adherence to TB treatment, an array of additional solutions is needed. More health facilities that offer complete care, and are located closer to the place of residents of patients, are needed. Patients undergoing lengthy treatment regimens may also require transportation to care facilities, or perhaps delivery services. Though the evidence regarding the positive impacts of home delivery of TB treatment is limited, ${ }^{85}$ home delivery for treatment of other diseases has been shown to be impactful. ${ }^{86,87}$

Patients may need support so that they can cope with the severe physical and psychological side effects from drug regimens used to treat the most resistant strains of TB. ${ }^{10,73,74}$ Mental health care, including counselling, therapy, and prescribing of appropriate psychiatric treatment, can help patients deal with the treatment side-effects as well as with issues related to a lack of social support. ${ }^{75,76}$ The usage of integrated practice units (IPUs), which involve the usage of mental health services within TB facilities in the form of counselling sessions, has been shown to both improve mental health symptoms and increase TB treatment adherence rates. ${ }^{88}$ Scaling up of IPUs may therefore be an effective intervention for TB patients.

Reducing costs to patients and removing financial constraints for TB treatment is also critical to improving adherence rates, ${ }^{75-78}$ as numerous studies in this review have shown that individuals with low educational/socioeconomic standing tend to have worse outcomes. ${ }^{48,51,58,69}$ Lowering catastrophic costs, which are high expenses due to TB that exceed a certain threshold of total household income, ${ }^{89}$ will be crucial. Active case finding (ACF), a strategy utilizing approaches such as house-to-house outreach to find $\mathrm{TB}$ patients before they show major signs of illness, ${ }^{90}$ has shown promise as an intervention that can lower transmission rates, ${ }^{90}$ improve health outcomes, ${ }^{90,91}$ and reduce catastrophic costs for TB patients. ${ }^{90,92}$ ACF hence have the potential to serve as interventions that can contribute to prevention efforts and reduce the likelihood of poor outcomes by early detection, while also lowering financial burdens for patients. Cash transfer and microfinance programs, which have been implemented to address numerous health issues, may also have a role in improving TB outcomes for impoverished patients. ${ }^{93}$

While a number of the findings of our review are comparable to the previously mentioned review on risk factors for developing XDR-TB by Flor de Lima and Tavares, ${ }^{15}$ there are also important differences that need to be emphasized. In contrast to their findings, it is worth reiterating that this review showed that comorbidities greatly increase one's risk for poor outcomes, as does smoking, low BMI, being formerly incarcerated, and being immunocompromised. Our review also emphasizes that adverse reactions to XDR-TB drugs may increase one's risk for poor outcomes after developing XDR-TB, though more research is required. These differing findings indicate that the aforementioned factors may have a measurable impact on XDR-TB outcomes, but not necessarily for developing XDR-TB. More research is therefore needed to better understand the extent to which certain factors have on influence on developing XDR-TB, compared to an influence on patient outcomes.

Further investigation of the possible relationship between smoking and poor outcomes is also needed, and more explicit guidelines may be needed to advise DR-TB patients against smoking. An additional notable finding was that individuals who were most at risk of poor outcomes from XDR-TB were approximately 30-45 years of age. A possible explanation of why TB was more deadly for this relatively younger group, rather than for older individuals, is that they may be more likely to participate in risky behaviors and less likely to completely adhere to the arduous treatment regimen, perhaps due to financial constraints. It is worth further analyzing the role of age in future research.

This review included 25 studies from an array of geographic locations and cultural contexts, which increases the robustness of the overall findings. A number of these studies had relatively large sample sizes, with some incorporating thousands of individuals, thereby also increasing the robustness of the findings. Overall, the findings of the review provide avenues for future research and important insights to guide the development of policies and clinical guidelines.

Among the limitations to this review are the inconsistencies and variations in the way the articles reported results, making it difficult to compare the results of the different studies. Large confidence intervals across numerous findings require the usage of caution when interpreting results. There were also inherent limitations in terms of determining temporality. It is not known whether the 
mutable factors had occurred before diagnosis of TB, or simply before the patient died.

\section{Conclusion}

XDR-TB patients have a high risk for mortality overall. Our review highlights a number of important risk factors for poor outcomes including being a smoker, being a former prisoner, being middle-aged, being coinfected with HIV, and having a previous history of TB. These findings contribute to the literature by further emphasizing the urgency of ensuring that TB patients adhere to antimicrobial treatment until the pathogen is completely cleared, particularly among high-risk groups. As well, the findings indicate a need for future research to better understand other possible risk factors such as adverse events during treatment, specific comorbidities, and being an immigrant. In consideration of the enormity of the threat that XDR-TB poses, there is a very strong need for action to be taken.

\section{Acknowledgments}

The authors of this review would like to acknowledge Paul Hunter, DMD, MS, Jennifer Wilson, MS, ELS, and Amy Leader, DrPH, MPH for their insights and contributions. Publication was made possible in part by support from the Thomas Jefferson University Open Access Fund.

\section{Disclosure}

None of the authors have any conflicts of interest to disclose. No financial support was provided for this project.

\section{References}

1. World Health Organization. Global tuberculosis report 2019. Geneva: World Health Organization; 2019. Available from: https://apps.who. int/iris/bitstream/handle/10665/329368/9789241565714-eng.pdf?ua=1. Accessed September 8, 2021.

2. World Health Organization. Tuberculosis. Newsroom. World Health Organization; 2021a. Available from: https://www.who.int/news-room/ fact-sheets/detail/tuberculosis. Accessed October 13, 2021.

3. Centers for Disease Control. Highlights from the 2016 treatment of drug-susceptible tuberculosis guidelines; 2016. Available from: https:// www.cdc.gov/tb/topic/treatment/guidelinehighlights.htm\#: :text=The $\% 20$ preferred $\% 20$ regimen $\% 20$ for $\% 20$ treating,months $\% 20$ of $\% 20 \mathrm{INH}$ \%20and\%20RIF. Accessed April 18, 2021.

4. MacNeil A, Glaziou P, Sismanidis C, Maloney S, Floyd K. Global epidemiology of tuberculosis and progress toward achieving global targets-2017. MMWR Morb Mortal Wkly Rep. 2019;68(11):263. doi:10.15585/mmwr.mm6811a3

5. World Health Organization. WHO announces updated definitions of extensively drug-resistant tuberculosis; 2021b. Available from: https:// www.who.int/news/item/27-01-2021-who-announces-updated-defini tions-of-extensively-drug-resistant-tuberculosis. Accessed Sep tember 8, 2021.
6. World Health Organization. Update of the WHO guidance on the treatment of drug susceptible tuberculosis; 2021c. Available from: https://www.who.int/news/item/16-04-2021-update-of-the-who-gui dance-on-the-treatment-of-drug-susceptible-tuberculosis. Accessed November 1, 2021.

7. Centers for Disease Control and Prevention. Highlights from the 2016 treatment of drug-susceptible tuberculosis guidelines. Available from: https://www.cdc.gov/tb/topic/treatment/guidelinehigh lights.htm. Accessed November 1, 2021.

8. Manjelievskaia J, Erck D, Piracha S, Schrager L. Drug-resistant TB: deadly, costly and in need of a vaccine. Trans $R$ Soc Trop Med Hyg. 2016;110(3):186-191. doi:10.1093/trstmh/trw006

9. Johnston JC, Shahidi NC, Sadatsafavi M, Fitzgerald JM. Treatment outcomes of multidrug-resistant tuberculosis: a systematic review and meta-analysis. PLoS One. 2009;4(9):e6914. doi:10.1371/journal. pone. 0006914

10. Yang TW, Park HO, Jang HN, et al. Side effects associated with the treatment of multidrug-resistant tuberculosis at a tuberculosis referral hospital in South Korea: a retrospective study. Medicine. 2017;96 (28). doi:10.1097/MD.0000000000007482

11. Migliori GB, De Iaco G, Besozzi G, Centis R, Cirillo DM. First tuberculosis cases in Italy resistant to all tested drugs. Weekly Release. 2007;12(20):3194. doi:10.2807/esw.12.20.03194-en

12. Velayati AA, Masjedi MR, Farnia P, et al. Emergence of new forms of totally drug-resistant tuberculosis bacilli: super extensively drugresistant tuberculosis or totally drug-resistant strains in Iran. Chest. 2009;136(2):420-425. doi:10.1378/chest.08-2427

13. Udwadia ZF, Amale RA, Ajbani KK, Rodrigues C. Totally drugresistant tuberculosis in India. Clin Infect Dis. 2012b;54(4):579-581. doi:10.1093/cid/cir889

14. Klopper M, Warren RM, Hayes C, et al. Emergence and spread of extensively and totally drug-resistant tuberculosis, South Africa. Emerg Infect Dis. 2013;19(3):449. doi:10.3201/eid1903.120246

15. Flor de Lima B, Tavares M. Risk factors for extensively drug-resistant tuberculosis: a review. Clin Respir J. 2014;8(1):11-23. doi: $10.1111 /$ crj. 12044

16. Cohen T, Colijn C, Wright A, Zignol M, Pym A, Murray M. Challenges in estimating the total burden of drug-resistant tuberculosis. Am J Respir Crit Care Med. 2008;177(12):1302-1306. doi:10.1164/rccm.200801-175PP

17. Kompala T, Shenoi SV, Friedland G. Transmission of tuberculosis in resource-limited settings. Curr HIV/AIDS Rep. 2013;10(3):264-272. doi:10.1007/s11904-013-0164-x

18. Luepke KH, Suda KJ, Boucher H, et al. Past, present, and future of antibacterial economics: increasing bacterial resistance, limited antibiotic pipeline, and societal implications. Pharmacotherapy. 2017;37 (1):71-84. doi:10.1002/phar.1868

19. Sprigg K, Pietrangeli CE. Bacterial antibiotic resistance: on the Cusp of a post-antibiotic world. Curr Treat Options Infect Dis. 2019;11:42-57. doi:10.1007/s40506-019-0181-4

20. Dheda K, Gumbo T, Gandhi NR, et al. Global control of tuberculosis: from extensively drug-resistant to untreatable tuberculosis. Lancet Respir Med. 2014;2(4):321-338. doi:10.1016/S2213-2600(14) 70031-1

21. Gandhi NR, Nunn P, Dheda K, et al. Multidrug-resistant and extensively drug-resistant tuberculosis: a threat to global control of tuberculosis. Lancet. 2010a;375(9728):1830-1843. doi:10.1016/S01406736(10)60410-2

22. World Health Organization. Multidrug- and extensively drug-resistant TB (M/XDR-TB); 2021d. Available from: https://www.euro.who.int/ en/health-topics/communicable-diseases/tuberculosis/data-and-statis tics/multidrug-and-extensively-drug-resistant-tb-mxdr-tb. Accessed November 2, 2021.

23. Sotgiu G, Ferrara G, Matteelli A, et al. Epidemiology and clinical management of XDR-TB: a systematic review by TBNET. Eur Respir J. 2009;33(4):871-881. doi:10.1183/09031936.00168008 
24. Alemu A, Bitew ZW, Worku T, Gamtesa DF, Alebel A, Sabol I. Predictors of mortality in patients with drug-resistant tuberculosis: a systematic review and meta-analysis. PLoS One. 2021;16(6): e0253848. doi:10.1371/journal.pone.0253848

25. Tricco AC, Lillie E, Zarin W, et al. PRISMA extension for scoping reviews (PRISMA-ScR): checklist and explanation. Ann Intern Med. 2018;169(7):467-473. doi:10.7326/M18-0850

26. Page MJ, McKenzie JE, Bossuyt PM, Boutron I, Hoffmann TC, Mulrow CD, et al. The PRISMA 2020 statement: an updated guideline for reporting systematic reviews BMJ. 2021;372:n71. doi:10.1136/bmj.n71

27. Cox H, Hughes J, Black J, Nicol MP. Precision medicine for drugresistant tuberculosis in high-burden countries: is individualised treatment desirable and feasible? Lancet Infect Dis. 2018;18(9):e282e287. doi:10.1016/S1473-3099(18)30104-X

28. Jibrin YB, Ali AB, Saad ST, Kolo PM. Prevalence of treatment failure among pulmonary tuberculosis patients in federal medical centre, Gombe, Northeastern Nigeria. ISRN Infect Dis. 2013;2013:1-4. doi:10.5402/2013/461704

29. Ankrah AO, van der Werf TS, de Vries EF, Dierckx RA, Sathekge MM, Glaudemans AW. PET/CT imaging of Mycobacterium tuberculosis infection. Clin Transl Imaging. 2016;4(2):131-144. doi:10.1007/s40336-016-0164-0

30. Koul AN. MDRTB Then, XMDRTB Now and Then......... Totally. JMS. 2016;19(1):12-17. doi:10.33883/jms.v19i1.275

31. Tabarsi P, Mardani M. Extensively drug-resistant tuberculosis: a review article. Arch Clin Infect Dis. 2012;7(3):81-84. doi:10.5812/archcid.14773

32. Keshavjee S, Farmer PE. Tuberculosis, drug resistance, and the history of modern medicine. $N$ Engl J Med. 2012;367(10):931-936. doi:10.1056/NEJMra1205429

33. Abilleira F, Brum C, von Groll A, da Silva PE. Evaluation of direct microplate nitrate reductase assay as a rapid method for the detection of multiple and extensively tuberculosis drug resistance. Biomédica. 2015;35(2):285-291. doi:10.1590/S0120-41572015000200017

34. Kumwenda G, Chipungu G, Sloan D, Kaimila Y, Chiumya K, Pangani H. The occurrence and frequency of genomic mutations that mediate Isoniazid and Rifampicin resistance in Mycobacterium tuberculosis isolates from untreated pulmonary Tuberculosis cases in urban Blantyre, Malawi. Malawi Med J. 2018;30(1):1-5. doi:10.4314/mmj.v30i1.1

35. Dara M, Sotgiu G, Zaleskis R, Migliori GB. Untreatable tuberculosis: is surgery the answer? Eur Respir J. 2015;45(3):577-582. doi:10.1183/09031936.00229514

36. Banin E, Hughes D, Kuipers OP. Bacterial pathogens, antibiotics and antibiotic resistance. FEMS Microbiol Rev. 2017;41(3):450-452. doi:10.1093/femsre/fux016

37. Duffy ST. The power of detention in the management of non-compliance with tuberculosis treatment: a survey of Irish practitioners and analysis of potential legal liability. Public Health. 2009;123 (1):81-85. doi:10.1016/j.puhe.2008.09.001

38. Migliori GB, Centis R, D'Ambrosio L, et al. Totally drug-resistant and extremely drug-resistant tuberculosis: the same disease? Clin Infect Dis. 2012;54(9):1379-1380. doi:10.1093/cid/cis128

39. Amaral L, Molnar J. Potential therapy of multidrug-resistant and extremely drug-resistant tuberculosis with thioridazine. In Vivo. 2012;26(2):231-236.

40. Therese KL, Gayathri R, Madhavan HN. Molecular biological techniques for detection of multidrug resistant tuberculosis (MDR) and extremely drug resistant tuberculosis (XDR) in clinical isolates of Mycobacterium tuberculosis. In: Understanding Tuberculosis-global Experiences and Innovative Approaches to the Diagnosis. Rijeka, Croatia: InTech; 2012:455-470.

41. Dheda K, Limberis JD, Pietersen E, et al. Outcomes, infectiousness, and transmission dynamics of patients with extensively drug-resistant tuberculosis and home-discharged patients with programmatically incurable tuberculosis: a prospective cohort study. Lancet Respir Med. 2017b;5(4):269-281. doi:10.1016/S2213-2600(16)30433-7
42. Nathavitharana RR, Lederer P, Tierney DB, Nardell E. Treatment as prevention and other interventions to reduce transmission of multidrug-resistant tuberculosis. Int J Tuberc Lung Dis. 2019;23(4):396404. doi: $10.5588 /$ ijtld. 18.0276

43. Farnia P, Mohammad RM, Merza MA, et al. Growth and cell-division in extensive (XDR) and extremely drug resistant (XXDR) tuberculosis strains: transmission and atomic force observation. Int J Clin Exp Med. 2010;3(4):308.

44. Joanna Briggs Institute. Critical appraisal tools; n.d. Available from: https://jbi.global/critical-appraisal-tools. Accessed November 2, 2021.

45. Bowring AL, Veronese V, Doyle JS, Stoove M, Hellard M. HIV and sexual risk among men who have sex with men and women in Asia: a systematic review and meta-analysis. AIDS Behav. 2016;20 (10):2243-2265. doi:10.1007/s10461-015-1281-x

46. Xu Y, Chen X, Wang K. Global prevalence of hypertension among people living with HIV: a systematic review and meta-analysis. $J \mathrm{Am}$ Soc Hypertens. 2017;11(8):530-540. doi:10.1016/j.jash.2017.06.004

47. Adalbert JR, Varshney K, Tobin R, Pajaro R. Clinical outcomes in patients co-infected with COVID-19 and Staphylococcus aureus: a scoping review. BMC Infect Dis. 2021;21(1):1-17. doi:10.1186/ s12879-021-06616-4

48. Balabanova Y, Ignatyeva O, Fiebig L, et al. Survival of patients with multidrug-resistant TB in Eastern Europe: what makes a difference? Thorax. 2016;71(9):854-861. doi:10.1136/thoraxjnl-2015-207638

49. Balabanova Y, Nikolayevskyy V, Ignatyeva O, et al. Survival of civilian and prisoner drug-sensitive, multi- and extensive drug- resistant tuberculosis cohorts prospectively followed in Russia. PLoS One. 2011;6(6):e20531. doi:10.1371/journal.pone.0020531

50. Bei C, Fu M, Zhang Y, et al. Mortality and associated factors of patients with extensive drug-resistant tuberculosis: an emerging public health crisis in China. BMC Infect Dis. 2018;18(1):261. doi:10.1186/s12879-018-3169-7

51. Bhering M, Duarte R, Kritski A. Predictive factors for unfavourable treatment in MDR-TB and XDR-TB patients in Rio de Janeiro State, Brazil, 2000-2016. PLoS One. 2019;14(11):e0218299. doi:10.1371/ journal.pone.0218299

52. Blöndal K, Viiklepp P, Guomundsson LJ, Altraj A. Predictors of recurrence of multidrug-resistant and extensively drug-resistant tuberculosis. Int $J$ Tuberc Lung Dis. 2012;16(9):1228-1233. doi:10.5588/ijtld.12.0037

53. Chingonzoh R, Manesen MR, Madlavu MJ, et al. Risk factors for mortality among adults registered on the routine drug resistant tuberculosis reporting database in the Eastern Cape Province, South Africa, 2011 to 2013. PLoS One. 2018;13(8):e202469. doi:10.1371/journal.pone.0202469

54. Frank M, Adamashvili N, Lomtadze N, et al. Long-term follow-up reveals high post-treatment mortality among patients with extensively drug-resistant (XDR) tuberculosis in the country of Georgia. Open Forum Infect Dis. 2019;6. doi:10.1093/ofid/ofz152

55. Gandhi NR, Andrews JR, Brust JC, et al. Risk factors for mortality among MDR-and XDR-TB patients in a high HIV prevalence setting. Int J Tuberc Lung Dis. 2012;16(1):90-97. doi:10.5588/ijtld.11.0153

56. Gandhi NR, Shah NS, Andrews JR, et al. HIV coinfection in multidrug- and extensively drug-resistant tuberculosis results in high early mortality. Am J Respir Crit Care Med. 2010b;181(1):80-86. doi:10.1164/rccm.200907-0989OC

57. James P, Gupta R, Christopher DJ, Thankagunam B, Veeraraghavan B. MDR-and XDR-TB among suspected drug-resistant TB patients in a tertiary care hospital in India. Clin Respir J. 2011;5(1):19-25. doi:10.1111/j.1752-699X.2009.00184.x

58. Javaid A, Ullah I, Masud H, et al. Predictors of poor treatment outcomes in multidrug-resistant tuberculosis patients: a retrospective cohort study. Clin Microbiol Infect. 2018;24(6):612-617. doi:10.1016/j.cmi.2017.09.012 
59. Kuksa L, Riekstina V, Leimane V, et al. Multi-and extensively drugresistant tuberculosis in Latvia: trends, characteristics and treatment outcomes. Public Health Action. 2014;4(2):S47-S53. doi:10.5588/ pha. 14.0041

60. Kvasnovsky CL, Cegielski JP, Erasmus R, Siwisa NO, Thomas K, der Walt ML. Extensively drug-resistant TB in Eastern Cape, South Africa: high mortality in HIV-negative and HIV-positive patients. $J$ Acquir Immune Defic Syndr. 2011;57(2):146-152. doi:10.1097/ QAI.0b013e31821190a3

61. Liu CH, Li L, Chen Z, et al. Characteristics and treatment outcomes of patients with MDR and XDR tuberculosis in a TB referral hospital in Beijing: a 13-year experience. PLoS One. 2011;6(4):e19399. doi:10.1371/journal.pone.0019399

62. O’Donnell MR, Padayatchi N, Kvasnovsky C, Werner L, Master I, Horsburgh CR Jr. Treatment outcomes for extensively drug-resistant tuberculosis and HIV co-infection. Emerg Infect Dis. 2013;19 (3):416-424. doi:10.3201/eid1903.120998

63. O’Donnell MR, Pillay M, Pillay M, et al. Primary capreomycin resistance is common and associated with early mortality in patients with extensively drug-resistant tuberculosis in KwaZulu-natal, South Africa. $J$ Acquir Immune Defic Syndr. 2015;69(5):536-543. doi:10.1097/QAI.0000000000000650

64. Olayanju O, Limberis J, Esmail A, et al. Long-term bedaquilinerelated treatment outcomes in patients with extensively drug-resistant tuberculosis from South Africa. Eur Respir J. 2018;51(5):1800544. doi:10.1183/13993003.00544-2018

65. Pietersen E, Ignatius E, Streicher EM, et al. Long-term outcomes of patients with extensively drug-resistant tuberculosis in South Africa: a cohort study. Lancet. 2014;383(9924):1230-1239. doi:10.1016/ S0140-6736(13)62675-6

66. Pietersen E, Peter J, Streicher E, et al. High frequency of resistance, lack of clinical benefit, and poor outcomes in capreomycin treated South African patients with extensively drug-resistant tuberculosis. PLoS One. 2015;10(4):e0123655. doi:10.1371/journal.pone.0123655

67. Shean K, Streicher E, Pieterson E, et al. Drug-associated adverse events and their relationship with outcomes in patients receiving treatment for extensively drug-resistant tuberculosis in South Africa. PLoS One. 2013;8 (5):e63057. doi:10.1371/journal.pone.0063057

68. Shin SS, Keshavjee S, Gelmanova IY, et al. Development of extensively drug-resistant tuberculosis during multidrug-resistant tuberculosis treatment. Am J Respir Crit Care Med. 2010;182(3):426-432. doi:10.1164/rccm.200911-17680C

69. Tang S, Tan S, Yao L, et al. Risk factors for poor treatment outcomes in patients with MDR-TB and XDR-TB in China: retrospective multi-center investigation. PLoS One. 2013;8(12):e82943. doi:10.1371/journal.pone.0082943

70. Te Riele JB, Buser V, Calligaro G, et al. Relationship between chest radiographic characteristics, sputum bacterial load, and treatment outcomes in patients with extensively drug-resistant tuberculosis. Int J Infect Dis. 2019;79:65-71. doi:10.1016/j.ijid.2018.10.026

71. Yuengling KA, Padayatchi N, Wolf A, et al. Effect of antiretroviral therapy on treatment outcomes in a prospective study of extensively drug-resistant tuberculosis (XDR-TB) HIV coinfection treatment in KwaZulu-Natal, South Africa. J Acquir Immune Defic Syndr. 2018;79 (4):474-480. doi:10.1097/QAI.0000000000001833

72. Zhang L, Meng Q, Chen S, et al. Treatment outcomes of multidrugresistant tuberculosis patients in Zhejiang, China, 2009-2013. Clin Microbiol Infect. 2018;24(4):381-388. doi:10.1016/j.cmi.2017.07.008

73. Syakiratin Q, Wibowo A, Febriani E. Psychological challenges faced by multidrug-resistant tuberculosis patients: a systematic review. Berita Kedokteran Masyarakat. 2019;35(5):155-161.

74. Madhav B, Iyer A, Jayalakshmi TK. Side effect profile of 2nd line drugs in multi drug resistant (MDR) and extensively drug resistant (XDR) tuberculosis. Eur Respir J. 2015;46:PA2708. doi:10.1183/ 13993003.congress-2015.PA2708
75. Tola HH, Tol A, Shojaeizadeh D, Garmaroudi G. Tuberculosis treatment non-adherence and lost to follow up among TB patients with or without HIV in developing countries: a systematic review. Iran $J$ Public Health. 2015;44(1):1-11.

76. Widjanarko B, Gompelman M, Dijkers M, van der Werf MJ. Factors that influence treatment adherence of tuberculosis patients living in Java, Indonesia. Patient Prefer Adherence. 2009;3:231-238. doi:10.2147/ppa.s6020

77. Gebremariam MK, Bjune GA, Frich JC. Barriers and facilitators of adherence to TB treatment in patients on concomitant TB and HIV treatment: a qualitative study. BMC Public Health. 2010;10(1):651. doi:10.1186/1471-2458-10-651

78. Chimbindi N, Bor J, Newell ML, et al. Time and money: the true costs of health care utilization for patients receiving "Free" HIV/ tuberculosis care and treatment in rural KwaZulu-Natal. J Acquir Immune Defic Syndr. 2015;70(2):e52-e60. doi:10.1097/QAI.00 00000000000728

79. Central Intelligence Agency (CIA). HIV/AIDS - people living with HIV/AIDS. CIAWorld Factbook; 2020. Available from: https://www. cia.gov/the-world-factbook/field/hiv-aids-people-living-with-hivaids/country-comparison. Accessed December 7, 2021.

80. World Health Organization. Drug-resistant TB: totally drug-resistant TB FAQ. Areas of work: World Health Organization; 2020. Available from: https://www.who.int/tb/areas-of-work/drug-resistant-tb/totallydrug-resistant-tb-faq/en/. Accessed April 22, 2020.

81. World Health Organization. Drug-resistant TB: XDR-TB FAQ. World Health Organization; 2020. Available from: https:/www. who.int/tb/areas-of-work/drug-resistant-tb/xdr-tb-faq/en/. Accessed June 3, 2020.

82. de Almeida CPB, Ziegelmann PK, Couban R, Wang L, Busse JW, Silva DR. Predictors of in-hospital mortality among patients with pulmonary tuberculosis: a systematic review and meta-analysis. Sci Rep. 2018;8(1):1-8. doi:10.1038/s41598-018-25409-5

83. Waitt CJ, Squire SB. A systematic review of risk factors for death in adults during and after tuberculosis treatment. Int J Tuberc Lung Dis. 2010;15:871-885. doi:10.5588/ijtld.10.0352

84. World Health Organization. Addressing TB comorbidities and healthrelated risk factors; 2021e. Available from: https://www.who.int/activ ities/addressing-tb-comorbidities-and-health-related-risk-factors. Accessed November 2, 2021.

85. Stockbridge EL, Kabani FA, Gallups JS, Miller TL. Ramadan and culturally competent care: strengthening tuberculosis protections for recently resettled Muslim refugees. J Public Health Manag Pract. 2020;26(5):E13-E16. doi:10.1097/PHH.0000000000000893

86. Hoke T, Bateganya M, Toyo O, et al. How home delivery of antiretroviral drugs ensured uninterrupted HIV treatment during COVID19: experiences from Indonesia, Laos, Nepal, and Nigeria. Global Health: Science and Practice; 2021.

87. Mash R, Christian C, Chigwanda RV. Alternative mechanisms for delivery of medication in South Africa: a scoping review. S Afr Fam Pract. 2021;63(1). doi:10.4102/safp.v63i1.5274

88. Pasha A, Siddiqui H, Ali S, Brooks MB, Maqbool NR, Khan AJ. Impact of integrating mental health services within existing tuberculosis treatment facilities. Med Access Point Care. 2021;5:23992026211011314. doi:10.1177/23992026211011314

89. World Health Organization. Tuberculosis patient cost surveys: a handbook. Geneva: World Health Organization; 2017. Available from: https:// apps.who.int/iris/handle/10665/259701. Accessed November 2, 2021.

90. Gurung SC, Dixit K, Rai B, et al. The role of active case finding in reducing patient incurred catastrophic costs for tuberculosis in Nepal. Infect Dis Poverty. 2019;8:99. doi:10.1186/s40249-019-0603-z

91. World Health Organization. Mozambique - a comprehensive community-based delivery intervention for TB. Available from: https:// apps.who.int/iris/bitstream/handle/10665/337105/9789240013575eng.pdf. Accessed November 2, 2021. 
92. Vo LNQ, Forse RJ, Codlin AJ, et al. Socio-protective effects of active case finding on catastrophic costs from tuberculosis in Ho Chi Minh City, Viet Nam: a longitudinal patient cost survey. BMC Health Serv Res. 2021;21(1):1-11. doi:10.1186/s12913-021-06984-2
93. Boccia D, Hargreaves J, Lönnroth K, et al. Cash transfer and microfinance interventions for tuberculosis control: review of the impact evidence and policy implications. Int J Tuberc Lung Dis. 2011;15 (Suppl2):37-49. doi:10.5588/ijtld.10.0438

\section{Publish your work in this journal}

Infection and Drug Resistance is an international, peer-reviewed openaccess journal that focuses on the optimal treatment of infection (bacterial, fungal and viral) and the development and institution of preventive strategies to minimize the development and spread of resistance. The journal is specifically concerned with the epidemiology of

Submit your manuscript here: https://www.dovepress.com/infection-and-drug-resistance-journal antibiotic resistance and the mechanisms of resistance development and diffusion in both hospitals and the community. The manuscript management system is completely online and includes a very quick and fair peerreview system, which is all easy to use. Visit http://www.dovepress.com/ testimonials.php to read real quotes from published authors. 